\title{
The Promise and Failures of Children's Medicaid and the Role of Medical-Legal Partnerships as Monitors and Advocates
}

L. Kate Mitchell

Follow this and additional works at: https://scholarlycommons.law.case.edu/healthmatrix

Part of the Health Law and Policy Commons, and the Medical Jurisprudence Commons

\section{Recommended Citation}

L. Kate Mitchell, The Promise and Failures of Children's Medicaid and the Role of Medical-Legal Partnerships as Monitors and Advocates, 30 Health Matrix 175 (2020)

Available at: https://scholarlycommons.law.case.edu/healthmatrix/vol30/iss1/6

This Article is brought to you for free and open access by the Student Journals at Case Western Reserve University School of Law Scholarly Commons. It has been accepted for inclusion in Health Matrix: The Journal of LawMedicine by an authorized administrator of Case Western Reserve University School of Law Scholarly Commons. 


\title{
The Promise and Failures of Children's MEDiCAID AND THE ROLE OF MEDICAL-LEGAL PARTNERSHIPS AS MONITORS AND Advocates
}

\author{
L. Kate Mitchell
}

\begin{abstract}
For decades we have known that access to early and preventive diagnosis and treatment can dramatically alter the course of a child's life. Because of this knowledge, immediately after Congress enacted Medicaid, it created the Early and Periodic Screening, Diagnostic and Treatment, or EPSDT, program. EPSDT requires broad, holistic, and preventive care to correct or ameliorate health defects identified in Medicaid-eligible children. This coverage currently extends to 2 out of 5 children in the United States, and 47 percent of children with special health care needs. Because of the broad parameters of coverage mandated by EPSDT, Medicaid-eligible children should receive more enhanced access to care than adults on Medicaid, including any and all necessary medical care indicated by their health care providers. Tragically, for children like Savannah, a Medicaideligible girl with complex medical needs in Michigan, failures in

Clinical Professor of Law and Director of the Health Justice Project, a medical-legal partnership clinic at the University of Loyola Chicago School of Law. Professor Mitchell has over nineteen years of experience practicing poverty law with expertise in health law, special education, and interdisciplinary advocacy. She has educated hundreds of health care providers about EPSDT (Children's Medicaid) and engaged in EPSDT litigation and policy work in Ohio, Michigan, and Illinois. For their support in preparation of this article, Professor Mitchell thanks her research assistants, Krystal Tysdal, Sei Unno, Amanda Merkwae, and Kathleen Craddock. Thanks to Robert Dinnerstein, Sara Gold, Jennifer Rosen Valverde, and Naomi Mann for their feedback and comments as part of the NYU Clinical Writers' Workshop and much appreciation to Frank Vandervort, Aneel Chablani, Nadia Sawicki, and Kristin Hildebrant for their encouragement and comments on drafts.
\end{abstract}


EPSDT implementation resulted in unmet needs and dire consequences. Savannah was denied access to physical therapy, occupational therapy, and speech therapy critical to maintaining her ability to walk, feed herself, and function with some independence. As states have modified their Medicaid plan guidelines and transitioned to privatized Medicaid in an effort to cut growing costs, coverage gaps for vulnerable children like Savannah have intensified, leaving parents and providers feeling helpless and unable to give their patients and children the care they need.

Medical-legal partnerships - interdisciplinary collaborations between health care providers and lawyers - are well suited to monitor EPSDT compliance, engage medical providers in informed patient advocacy, facilitate exchange of information regarding failures in coverage, and hold Medicaid programs accountable to low-income children. This article will review the history of the public health insurance system, outline the current legal mandates and landscape of EPSDT, and discuss the role that medical-legal partnerships can play in ensuring that EPSDT fulfills its purpose.

\section{Contents}

INTRODUCTION

I. A Brief History of Public Health Care for Children

A. The Evolution of Hospitals, Charity Care, and Modern Medical Care.....

B. The Development of Publicly Funded Health Care for Children 182

II. The Legal Mandates of Children's Medicaid .............. 187

A. State Implementation of EPSDT ....................................... 190

B. Medical Advancements................................................ 197

1. Transplants ................................................ 199

2. ABA Therapy ........................................................... 200

3. Mental Health Treatment .......................................... 203

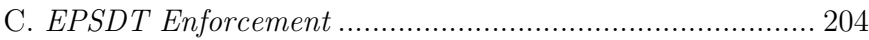

III. Current Medicaid Landscape ....................................... 206

IV. Medical-Legal Partnerships as EPSDT Monitors and Advocates

A. Medical-Legal Partnerships as Leaders in Patient Advocacy 
Health Matrix · Volume $30 \cdot 2020$

The Promise and Failures of Children's Medicaid and the Role of Medical-Legal Partnerships as Monitors and Advocates

B. The MLP Model and Opportunities for Upstream Systems

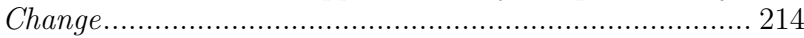

C. MLPs and EPSDT Advocacy ...................................... 216

1. Synagis Access in Ohio......................................... 220

2. Related Therapy Access in Michigan ....................... 223

3. Pediatric Hospital Bed Access in Ohio...................... 225

4. MLPs as EPSDT Monitors and Advocates ............... 227

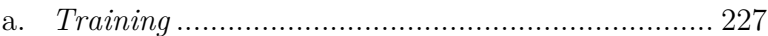
b. Encourage and Facilitate Provider Advocacy...... 228
c. Engage in Direct ESPDT Advocacy................... 230
d. Engage in Upstream Advocacy............................ 230

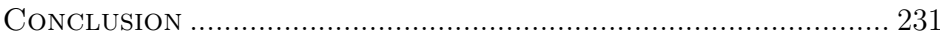

\section{INTRODUCTION}

The broad and expansive children's Medicaid program, Early and Periodic Screening, Diagnostic and Treatment, otherwise known as EPSDT, was first enacted by Congress in 1967, one year after Medicaid was devised as a part of the Social Security Act. ${ }^{1}$ EPSDT was developed as a separate and distinct program out of recognition that broader, comprehensive, and preventive health care could significantly impact the lives and opportunities of young people challenged by poverty. ${ }^{2}$ As such, EPSDT requires broad health care coverage for Medicaid eligible children, above and beyond the coverage required for adults, including periodic screenings or checkups, diagnostic testing, and all medical services

1. See 42 U.S.C. $\S \S 1396 \mathrm{a}(\mathrm{a})(10), \quad 1396 \mathrm{a}(\mathrm{a})(43), \quad 1396 \mathrm{~d}(\mathrm{a})(4)(\mathrm{B})$, 1396d(r)(5) (2019); Social Security Amendments of 1967, Pub. L. No. 90-248, 81 Stat. 929 (1968) (codified as amended at 42 U.S.C. $\S 1396(\mathrm{a})$ ); Jonathan Engel, Poor People's Medicine 55-9 (2006) (explaining that Medicaid-Title XIX of the Social Security Act - was enacted in 1965 as part of President Lyndon B. Johnson's "War on Poverty," a sweeping array of social-services programs).

2. See 42 C.F.R. $\S 441.56$ (2018) (listing required activities of EPSDT); See generally 42 U.S.C. § 1396(a) (2019) (presenting the requirements for medical assistance state plans); Stanton v. Bond, 504 F.2d 1246, 1247 (7th Cir. 1974) ("The addition of 'early and periodic screening and diagnosis' and 'treatment' (EPSDT) of persons under the age of 21 was the result of a growing need for child health care among the needy."). 
necessary to correct or ameliorate identified health defects. ${ }^{3}$ Because of the broad parameters of coverage outlined in EPSDT, eligible children should receive any and all necessary medical care indicated by their health care providers. ${ }^{4}$ Tragically, failures in EPSDT implementation have resulted in denials of medically necessary services, expenditures of significant health provider time on paperwork and appeals, revenue losses for children's hospitals and pediatric providers and, most importantly, lack of appropriate care for children. ${ }^{5}$ As states have continued to transition to privatized Medicaid through contracts with Medicaid Managed Care Organizations to serve the needs of children with complex medical needs, these coverage gaps have intensified, ${ }^{6}$ leaving parents and providers feeling helpless from not being able to give their patients and children the care they need. These consequences are particularly acute for children with complex medical needs, rare conditions, and those requiring long term therapies and costly medical equipment and medications. ${ }^{7}$ Medical-legal partnerships - interdisciplinary collaborations between health care providers and lawyers - are well suited to monitor EPSDT compliance, engage medical providers in informed patient advocacy, facilitate exchange of information

3. 42 U.S.C. $\$ 1396 \mathrm{~d}(\mathrm{r})(5)$ (2019) ("[S]uch other necessary health care ...").

4. Ctrs. For Medicare and Medicaid Servs., EPSDT - A Guide For States: Coverage in the Medicaid Benefit for Children AND ADOLESCENTS 1 (June 2014) [hereinafter EPSDT GuIDE FOR States]; See Anne-Marie Foltz, The Development of Ambiguous Federal Policy: Early and Periodic Screening, Diagnosis and Treatment (EPSDT), 53 MiLBANK Q. 35, 55-6 (1975) (discussing the broad and comprehensive nature of EPSDT).

5. See John A. Flippen, The Early and Periodic Screening, Diagnostic, and Treatment Program and Managed Medicaid Mental Health Care: The Need to Reevaluate the EPSDT in the Managed Care Era, 50 VAND. L. REV. 683, 685 (1997) (discussing how implementation may diminish the effectiveness of the EPSDT).

6. Marsha Gold \& Jessica Mittler, "Second-Generation" Medicaid Managed Care: Can it Deliver?, 22 Health Care Fin. Rev. 29, 4041, 44 (2000).

7. See Jane Perkins \& Rishi Agrawal, Protecting Rights of Children with Medical Complexity in an Era of Spending Reduction, 141 PEDIATRICS S242, S243 (2018). 
regarding coverage failures, and hold Medicaid programs accountable to low-income children.

Part I of this article will briefly review the history of the public health insurance system in the United States, discussing its strong focus on prioritizing health care for children. Part II will outline the current legal mandates of the EPSDT program and the expansive benefits it guarantees to eligible children. Part III will discuss the current landscape of Medicaid implementation, the move towards privatization of Medicaid through state contracts with Medicaid managed care organizations and its impact on EPSDT implementation, procedures for coverage determinations, and issues related to denials of coverage for care. Finally, Part IV will discuss the unique role that medical-legal partnerships can play in monitoring EPSDT and advocating to ensure access to quality health care for vulnerable children.

\section{A Brief History of Public Health Care for ChILDREN}

Throughout the history of medicine, there has been a strong focus on prioritizing care to vulnerable children, initially out of a desire to provide charitable services to the poor and later spurred by evidence-based research revealing the critical importance of early and preventive medical interventions and treatments for children. ${ }^{8}$ Further, the history of medical advancements coincides with the development of health insurance programs to assist with the correlating rising cost of medical care. ${ }^{9}$ Throughout this history, methods of providing care to people in poverty have evolved, leading to the development of publicly funded health insurance programs like Medicaid. Publicly funded health insurance for people in poverty, the elderly, children, and people with disabilities has grown through time, resulting in a complex web of systems of eligibility determinations, administrative oversights, and coverage limitations. As various forms of publicly funded health care have evolved, care for children, specifically

8. Cynthia A. Connolly, Late-Nineteenth and Early Century Pediatrics, Penn Nursing, https://www.nursing.upenn.edu/nhhc/ home-create/late-nineteenth-and-early-century-pediatrics/ [https://perma.cc/S4TD-HCA3] (last visited Oct. 17, 2019).

9. ENGEL, supra note 1, at 14-15. 
children with disabilities and children in poverty, continues to be a priority. ${ }^{10}$

\section{A. The Evolution of Hospitals, Charity Care, and Modern Medical Care}

The first private hospitals were developed by religious charitable institutions to promote collaboration among physicians and to care for the "deserving" poor, including widows, their children, and orphans. ${ }^{11}$ Public hospitals emerged in the late $19^{\text {th }}$ Century to provide primarily non-medical care to the "underserving" poor, vagrants, shelterless migrants, and seamen, and to maintain public order by keeping undesirables off of the streets. ${ }^{12}$ As medical advancements led to the development of actual treatments for medical conditions, private hospitals transformed and began providing medical procedures to those with the means to pay for it, moving away from the charity care of their roots. ${ }^{13}$ Once private hospitals shifted their focus to

10. See generally U.S. DeP'T of Health And Hum. Serv's Admin., Maternal and Child Health Bureau, Understanding Title V OF THE SOCIAL SECURITY ACT, available at http://www.amchp.org/ AboutTitleV/Documents/UnderstandingTitleV.pdf [http://perma .cc/HQ5U-VRWJ] (last visited Feb. 24, 2018) [hereinafter Understanding Title V]; See Foltz, supra note 4, at 40-42; RogER Manella \& Eugene Feingold, U.S. DeP'T OF Health, EduC., AND Welfare, A Brief History of the Medicaid EARly AND Periodic Screening Diagnosis and Treatment Program 3 (1977), available at https://archive.org/details/briefhistoryofme00 mane [https://perma.cc/79CH-VYRR] (last visited Feb. 24, 2018) [hereinafter A Brief History of Medicaid EPSDT]; Katherine B. Oettinger, Title $V$ of the Social Security Act: What It Has Meant to Children, 23 Soc. SEC. Bull. 39, 40 (1960).

11. Oettinger, supra note 10, at 8-9; Robert A. Moffitt, The Deserving Poor, the Family, and the U.S. Welfare System, 52 DEMOGRAPHY 729, 745-47 (2015).

12. ENGEL, supra note 1, at 10-11.

13. Id. at 12-13; Elizabeth H. Bradley \& Lauren A. Taylor, The American Health Care Paradox: Why Spending More is Getting us Less 23, 25, 27 (1st ed. 2013) (detailing Louis Pasteur's development of germ theory in 1862, and how it led to an understanding that germs caused diseases, which allowed progress in treatments of disease; and, that the development of anesthesia in 1846 and X-Rays in 1895 allowed for the advancement of surgery; 
medical care, care for those in poverty transferred solely to the public hospitals. ${ }^{14}$ Over time, as medical advancements continued to progress and the cost of medical procedures rose to exceed the salaries of working Americans, hospital insurance was created for those who could afford to purchase it. ${ }^{15}$ The first health insurance plan was created by Baylor University for teachers in 1927 to address revenue issues for Baylor University hospital resulting from unpaid bills from teachers. ${ }^{16}$ In 1939, the first Blue Shield Plan was established to cover physician services. ${ }^{17}$

Studies conducted in the $1950 \mathrm{~s}$ and $1960 \mathrm{~s}$ revealed that people with health insurance had better access to health care and better outcomes from illness and trauma. ${ }^{18}$ Further research revealed that one in six Americans could not work or engage in the daily activities of life due to chronic disease, disability, cognitive delay, or alcoholism. ${ }^{19}$ Policy makers began to realize that the poor were getting sicker and the sick were getting poorer. ${ }^{20}$ It became clear that social service programs were needed to increase access to health care and improve the health and productivity of working-aged adults. ${ }^{21}$

and, the discovery of penicillin in 1928 and sulfa drugs in the 1930's further advanced the ability to "manage disease.").

14. ENGEL, supra note 1 , at $12-13$.

15. Id. at 3-4 (noting the first hospital-based insurance plan emerged in the late 1920s).

16. BRADley \& TAYLOR, supra note 13 , at $28-9$.

17. Id. at 29 .

18. ENGEL, supra note 1 , at 4 .

19. Id. at 7 .

20. Id. at 6-7.

21. See President's Task Force on Manpower Conservation, OneThird OF A NATION, A REPORT ON Young Men Found Unqualified FOR MiLitary Service (1964) [hereinafter OneTHIRD OF A NATION]. 


\section{B. The Development of Publicly Funded Health Care for Children}

The first efforts to provide publicly funded health care in the United States were targeted at children. ${ }^{22}$ In 1935, as part of the New Deal, Title V of the Social Security Act created the first federally funded health care services program providing states grants for maternal and child health initiatives and for "crippled children's" programs. ${ }^{23}$ This program aimed to improve the identification of children in need of services and provide necessary medical, surgical, and corrective services. ${ }^{24}$ Under this program, block grants are given to states to provide health care and related services to pregnant women, infants, and children with disabilities and chronic medical conditions. ${ }^{25}$ These grants, which cede discretion to states on how to use these funds and whether to impose income guidelines, continue today and are used by many states to supplement health insurance for children with disabilities or special health care needs, provide non-medical supportive services such as respite care, translation, outreach, screenings and sudden infant death counseling, and infrastructure development. ${ }^{26}$ This program has endured for over half a century and "[s]ixty-five years later, Title V remains the longest lasting public health legislation in our Nation's history. Created as broad-sweeping social rather than health legislation, the legacies of Title $\mathrm{V}$ programs are deep and widespread." ${ }^{27}$

A few decades later, in 1965, as part of the wave of social programs developed under Lyndon B. Johnson's War on Poverty, Congress created Medicaid-Title XIX of the Social Security Act. ${ }^{28}$ Medicaid initially provided health care benefits to children in households receiving welfare, then called Aid to Families with Dependent Children (AFDC), and gave states the option to

22. See Understanding Title V, supra note 10; Cindy Mann et al., Historical Overview of Children's Health Care Coverage, 13 Future Child 31, 31 (2003).

23. See 42 U.S.C. $\S \S 701-710$ (2019); See Understanding Title V, supra note 10 , at iv.

24. A Brief History of MedicAid EPSDT, supra note 10, at 3.

25. Oettinger, supra note 10 , at 25.

26. See Understanding Title $V$, supra note 10 , at 3 .

27. Id. at iv.

28. See generally 42 U.S.C. § 1396 (2019). 
expand Medicaid coverage to all low income young people under the age of twenty-one. ${ }^{29}$ The purpose of Medicaid was "to expand the services for maternal and child health, crippled children, child welfare, and the mentally retarded ..." ${ }_{30}$ From its inception, participation in the Medicaid program has been voluntary for states, but "[o]nce a State voluntarily chooses to participate in Medicaid, the State must comply with the requirements of Title XIX and applicable regulations." ${ }^{31}$ Unfortunately, even after the implementation of Medicaid, many poor children were ineligible for Medicaid services due to state limitations on income eligibility and the lack of benefits for children not on AFDC. ${ }^{32}$

President Johnson, intending from the beginning of his presidency to make expanded health benefits for the poor and elderly one of his legacies ${ }^{33}$ continued to push for comprehensive health coverage for children in poverty. In 1967, President Johnson delivered an address to Congress recommending "a comprehensive program for American children" and specifically "calling for programs providing early diagnosis and treatment of children with handicaps." 34 This call for early diagnosis and treatment was driven, in part, by a federal government report revealing pervasive disqualifying disabilities among military recruits, ${ }^{35}$ as well as findings from health services research conducted through Head Start programs exposing the great need

29. A Brief History of MedicAid EPSDT, supra note 10, at 2.

30. S. Rep. No. 89-404 (1965) (Conf. Rep.).

31. Alexander v. Choate, 469 U.S. 287, 289 (1985).

32. U.S. Dep'T of Health, Educ. and Welfare, EPSDT: The Possible Dream 3 (1977), available at https://archive.org/ stream/epsdtpossibledre00unit/epsdtpossibledre00unit_djvu.txt [https://perma.cc/6MQY-UK3T].

33. ENGEL, supra note 1, at 44 .

34. Stanton v. Bond, 504 F.2d 1246, 1247 (7th Cir. 1974); See also President Lyndon B. Johnson, Special Message to the Congress Recommending a 12-Point Program for America's Children and Youth (Feb. 8, 1967), in Lyndon B. Johnson: 1967 (in two books): Containing the Public Messages, Speeches, and Statements of the President, 1 Pub. PAPERS 150 (1968).

35. One-ThiRd OF A NATiOn, supra note 21. 
for health care for young children. ${ }^{36}$ These studies fueled the realization that the absence of preventive-medical care for children leads to debilitating conditions in working-aged adults. ${ }^{37}$ Accordingly, Congress passed the Social Security Amendments of 1967, also known as H.R. 5710, which "created broad-ranging changes in the Social Security Act programs, of which the child health provisions formed only a small part." ${ }^{38}$ Through these amendments, substantive coverage for Medicaid-eligible children was expanded to include EPSDT services. ${ }^{39}$ The development of a separate EPSDT program reflected a clear recognition that children needed, and were deserving of, more expansive health care services than adults. ${ }^{40}$

Further regulations and guidelines implementing EPSDT were issued in 1972 and 1973, requiring States to take "aggressive steps to screen, diagnose and treat children with health problems." ${ }^{11}$ The guidelines clearly indicated to states that full implementation of EPSDT was required and that "[C]ongress was concerned about the variations from State to State in the rates of children treated for handicapping conditions and health problems that could lead to chronic illness and disability." ${ }^{42}$ While a preliminary draft of the children's Medicaid regulations only

36. Children's Defense Fund, EPSDT: Does It Spell Health Care FOR POOR CHILDREN? 92-94 (1977).

37. See Bruno Lunefeld et al., The Clinical Consequences of an Ageing World and Preventative Strategies, 27 Best PRAC. \& RES. ClinICAL OBSTETRICS \& GYNAECOLOGY 4-5 (2013).

38. Foltz, supra note 4 , at 42.

39. See 42 U.S.C. $\S \S 1396 a(a)(10), \quad 1396 a(a)(43), \quad 1396 \mathrm{~d}(\mathrm{a})(4)(\mathrm{B})$, 1396(r)(5) (2019).

40. J.E. v. Wong, No. 14-00399, 2016 WL 4275590, at *9 (D. Haw. Aug. 12, 2016) ("Congress deliberately crafted an 'extremely broad' EPSDT mandate to ensure that the poorest children and young adults have access to modern medical services."); MaryBeth Musumeci, Medicaid and the Uninsured: A Guide to the Medicaid Appeals Process, KaIser Comm'N (Mar. 29, 2012), https:// www.kff.org/wp-content/uploads/2013/01/8287.pdf [https://perma.cc/9URH-PLGJ].

41. Stanton v. Bond, 504 F.2d 1246,1248-49 (7th Cir. 1974) (citing Medical Assistance Manual, part 5, Section 5-70-00 et seq. (MSAPRG-21)).

42. Id. at 1249 . 
provided screening and diagnostic services, "Congress directed the Secretary of Health and Human Services to promulgate regulations defining the specific services that would be available for treatment of conditions identified during a health screen." 43

By 1989, many states still had not developed Medicaid plans extending full EPSDT coverage to Medicaid eligible children. ${ }^{44}$ Congress made efforts to again clarify its intent that states provide a broad range of health care services to young Medicaid recipients by expanding the definition of medical assistance under EPSDT, clarifying that states must provide all health care services listed under $\$ 1396 \mathrm{~d}(\mathrm{a})$ when necessary to correct or ameliorate health defects and illnesses identified in a screening whether or not those services were provided in the state plan. ${ }^{45}$ When states still didn't comply, advocates called on courts to intervene to force states to comply. In S.D. ex rel. Dickson v. Hood, the fifth circuit determined that the 1989 EPSDT amendment to the Social Security Act "imposed a mandatory duty upon participating states to provide EPSDT-eligible children with all the health care, services, treatments and other measures described in $\$ 1396 \mathrm{~d}(\mathrm{a})$ of the Act." 46 This case crystalized Congress's intent that states provide all allowable Medicaid covered services for children when medically necessary under EPSDT's guidelines. ${ }^{47}$ Two years later, the Centers for Medicare and Medicaid Services (CMS) clarified that "any service[] which you [states] are permitted to cover under Medicaid that is necessary to treat or ameliorate a defect, physical and

43. Statement of Interest of the U.S. at 5, in John B. v. Emkes, 710 F.3d 394 (6th Cir. 2013) (emphasis in original).

44. S.D. ex rel. Dickson v. Hood, 391 F.3d 581, 589 (5th Cir. 2004) (quoting Senate Finance Committee Report, 135 Cong. Rec. 24444 (Oct. 12, 1989)) ("The EPSDT benefit package has never been described in detail in the statute . . Additionally, while states have always had the option to do so, many still do not provide to children participating in EPSDT all care and services allowable under federal law, even if not otherwise included in the state's plan.").

45. Id. at 589 (citing 42 U.S.C. $\S 1396(\mathrm{r})(5))$.

46. Id. at 589-590 (citing 42 U.S.C. $§ 1396 \mathrm{~d}(\mathrm{r})(5)$ ).

47. Id. at 590 (citing 135 Cong. Rec. 13234 (Oct. 12, 1989) and H.R. Conf. Rep. 101-386, at 453 (1989)); 135 Cong. Rec. S6900 (June 19, 1989) (statement of Sen. Chafee). 
mental illness, or a condition identified by a screen, must be provided to EPSDT participants regardless of whether the service is otherwise included in your Medicaid plan."48 Though states have discretion to limit coverage for some health care services for Medicaid eligible adults, these affirmations of the intent of the EPSDT Amendment to expand coverage to children by Congress, the courts, and CMS left no doubt that states must provide children with expanded health care coverage.

In 1996, Congress further expanded health insurance coverage for children by severing the link between cash welfare eligibility and Medicaid eligibility, allowing states to expand Medicaid coverage to children of working poor families with income exceeding cash welfare eligibility caps but insufficient to purchase health insurance. ${ }^{49}$ One year later, the State Children's Health Insurance Program (CHIP) was passed. ${ }^{50} \mathrm{CHIP}$ encouraged states to expand Medicaid coverage to children of working poor families or develop alternative state-run health insurance programs to offer health insurance coverage to low-income children otherwise financially ineligible for Medicaid. ${ }^{51}$ These efforts paved the way to an increase in the number of children enrolled in Medicaid and eligible for EPSDT coverage. ${ }^{52}$ In 2019, approximately thirty-nine

48. S.D. v. Hood, 391 F.3d at 591 (citing CTRS. FOR MEDicare \& Medicaid Serv., State Medicaid Manual $§ 5110$ (1990)).

49. Mann et al., supra note 22, at 36-37; A Brief History of the AFDC Program, U.S. DEP'T OF HEALTH AND Hum. SERV's, https:// aspe.hhs.gov/system/files/pdf/167036/1history.pdf [https:// perma.cc/W5XF-ZW5D] (last visited Feb. 24, 2019).

50. History and Impact of CHIP, MEDICAID \& CHIP PAYMENT \& ACCESS COMM'N, https://www.macpac.gov/subtopic/history-andimpact-of-chip/ [https://perma.cc/5TXG-RH5P] (last visited Feb. 11, 2019); See generally Eugene Lewit, The State Children's Health Insurance Program (CHIP), in THE FUTURE OF CHILDREN 152-58 (1998).

51. See Lewit, supra note 50, at 152-158.

52. Medicaid and CHIP, NAT'L CONF. OF St. LeGIS., http://www.ncsl .org/research/health/medicaid-and-chip.aspx [https://perma.cc/ XT2S-MUXY] (last visited Feb. 24, 2019); Early and Periodic Screening, Diagnostic, and Treatment, MEDICAID, https://www. medicaid.gov/medicaid/benefits/epsdt/index.html [https://perma .cc/J7DZ-J8LS] (last visited Oct. 20, 2019). 
percent of children in the United States were covered by Medicaid and CHIP and forty-seven percent of children with disabilities and special healthcare needs were covered by Medicaid and CHIP. ${ }^{53}$

Because we know that health insurance and access to health care for children improves life-long health and the health of the working population, these continued expansions of Medicaid to children are critical to healthier communities and a more productive work force. Ensuring that the growing number of children covered by Medicaid receive the care they need is a critical next step.

\section{The Legal Mandates of Children's Medicaid}

EPSDT is intended to extend comprehensive preventive health care and a wide range of medically necessary services to Medicaid-eligible children. ${ }^{54}$ It ensures care to improve or maintain health in the best condition possible, compensate for a health problem, prevent a health problem from worsening, or to prevent the development of additional health problems. ${ }^{55}$ Under EPSDT, Medicaid-eligible children are entitled to coverage for all screenings, diagnostic testing, prescriptions, rehabilitative therapies, mental health services, medical equipment, nursing services, hospital care, and other necessary medical care prescribed by their health care providers. ${ }^{56}$ EPSDT is intentionally broad and provides eligible children and young people under the age of twenty-one with more expansive health coverage than is extended to Medicaid-eligible adults. ${ }^{57}$

Since its enactment, EPSDT has significantly enhanced access to pediatric health care and improved the health of low-

53. Medicaid: Putting United States Children on a Path to Success, Geo. U. Ctr. For Children and Families \& Am. Acad. of PEDIATRICS, https://downloads.aap.org/DOFA/Factsheets/ UnitedStatesSnapshot2019.pdf [https://perma.cc/9Y52-Y2AX] (noting that in 2017 and 2018, over one million children became uninsured, the first drops in coverage for children in a decade.)

54. EPSDT GUIDE FOR STATES, supra note 4 , at 1.

55. Id. at 2 .

56. Id.

57. Id. 
income children. National Medicaid expert Sara Rosenbaum called EPSDT "the single most important public policy effort ever undertaken to define an appropriate health services coverage standard embedded in developmental pediatric practice. ${ }^{158}$ Unlike Medicaid for adults, and private insurers that cover services focused on acute medical problems, EPSDT emphasizes preventive care to support child growth and development. ${ }^{59}$ EPSDT further places an affirmative duty on states to identify children in need of EPSDT services, arrange for the provision of services, cover necessary services, and coordinate services with non-Medicaid providers. ${ }^{60}$

Covered services for children under EPSDT include:

other diagnostic, screening, preventive, and rehabilitative services, including . . . any medical or remedial services . . . recommended by a physician or other licensed practitioner of the healing arts ... for the maximum reduction of physical or mental disability and restoration of an individual to the best possible functional level. ${ }^{61}$

In a report detailing EPSDT implementation over a 40-year period, Rosenbaum explained that EPSDT remains particularly important due to the fact that (1) chronic health conditions "account for the majority of pediatric hospitalizations and health care spending," and (2) the modern health care system is much better equipped to "detect, treat, manage, and reduce the impact

58. Sara Rosenbaum et al., EPSDT at Forty: Modernizing a Pediatric Health Policy to Reflect a Changing Health Care System, CTR. FOR Health Care Strategies, Inc. 1, 3 (2008), available at https://www.chcs.org/media/EPSDT_at_40.pdf [https://perma .cc/5D4J-3HDB] [hereinafter EPSDT at Forty].

59. EPSDT GUIDE FOR STATES, supra note 4 , at 1.

60. Memorandum from Sara Rosenbaum to Rita Vandivort, Substance Abuse \& Mental Health Serv's Admin. (Dec. 10, 2002) (on file with the George Wash. Univ. Med. Ctr. Ctr. For Health Serv's Research \& Pol'y); Meghan C. Casey, In Whose Hands Are We Placing Children's Health?: An Examination of "Medical Necessity" for Medicaid's EPSDT Provision, 29 J. CONTEMP. Health L. \& POL'Y 89, 94 (2013).

61. 42 U.S.C. $\S 1396 \mathrm{~d}(\mathrm{a})(13)(\mathrm{c})(2019)$. 
of (if not eliminate) chronic physical and mental conditions" affecting child development. ${ }^{62}$

While EPSDT has proven effective in expanding access to health coverage to vulnerable children, EPSDT - and Medicaid generally - is costly and has presented financial burdens for states. ${ }^{63}$ As medical advancements have continued, the Medicaid system has become financially burdened by a growing number of children with complex and chronic medical and developmental conditions, which in turn has caused states to struggle to balance costs with the breadth of medical care required under EPSDT. ${ }^{64}$ State Medicaid programs utilize state plan guidelines, policies, and preauthorization procedures to establish limits on coverage, manage expenditures, and monitor implementation. ${ }^{65}$ In my experience, state efforts to limit coverage can result in disputes between Medicaid plans and providers, administrative appeals by recipients, and protracted litigation. Some of these disputes stem from failures of the Medicaid system to keep up with medical advancements and changing standards of care, while others result from policies and practices which limit coverage as cost-saving measures. ${ }^{66}$ Issues with state efforts to limit coverage have led to extensive litigation and CMS guidance to states regarding EPSDT mandates. ${ }^{67}$ Despite enforcement efforts, however, conflicts over the scope of coverage under EPSDT continue. This section will provide an overview of the full range of services

62. EPSDT at Forty, supra note 58, at 4.

63. Mann et al., supra note 22, at 36 ("As eligibility expansions increased the number of children covered by Medicaid, states grew concerned about rising program costs and the availability of Medicaid providers to serve the new beneficiaries.").

64. See Pediatric Specialty Care, Inc. v. Ark. Dept. of Human Serv., 364 F.3d 925, 932 (8th Cir. 2004); Mitchell v. Johnston, 701 F.2d 337, 346 (5th Cir. 1983).

65. State Plan, Medicaid \& CHIP Payment \& ACCess Comm'N, https://www.macpac.gov/subtopic/state-plan/ [https://perma.cc/ 4LGT-QXJP] (last visited Feb. 24, 2019).

66. See Casey, supra note 60.

67. EPSDT Guide FOR STATES, supra note 4, at 1; Jane Perkins, Update on EPSDT Litigation Trends, Nati'L Health L. Program (Nov. 9, 2018), https://9kqpw4dcaw91s37kozm5jx17-wpengine .netdna-ssl.com/wp-content/uploads/2018/11/EPSDT-LitigationUpdate-IB-9.9.18.pdf [https://perma.cc/JJF5-J7LA]. 
required by EPSDT as outlined in federal law, agency guidance, and case law and will address some of the conflicts inherent in the system.

\section{A. State Implementation of EPSDT}

All states participating in the federal Medicaid program must implement a state plan that complies with federal rules and regulations. ${ }^{68}$ Currently, all states in the United States participate in Medicaid, with some variations in eligibility criteria, plan guidelines, and coverage. ${ }^{69}$ Medicaid is generally uniformly provided to young people who live in families with poverty-level income, those who receive Supplemental Social Security Income benefits due to a chronic and severe disability, and children in foster care or receiving adoption assistance. ${ }^{70}$ While states are permitted some flexibility in designing and implementing Medicaid programs for adults, EPSDT must be fully implemented for all Medicaid recipients under the age of twenty-one. ${ }^{71}$

To facilitate the comprehensive preventive system of health care required by EPSDT, states must create a state plan ${ }^{72}$ which

68. Mitchell, 701 F.2d at 340; Oklahoma v. Civil Serv. Comm'n, 67 S.Ct. 544 (1947) (establishing that Congress may "fix the terms" upon which it will disperse funds to states).

69. State Overviews, MEDICAID, https://www.medicaid.gov/stateoverviews [https://perma.cc/K78R-7G3U] (last visited Feb. 24, 2019).

70. Eligibility, DATA MEDICAID, https://data.medicaid.gov/Enrollment /State-Medicaid-and-CHIP-Applications-Eligibility-D/n5ce-jxme [https://perma.cc/3YJN-4ATA] (last visited Feb. 24, 2019); Total SSI Beneficiaries, KAISER FAM. FOUnD., https://www.kff.org/ medicaid/state-indicator/total-ssi-beneficiaries/ [https://perma.cc /VRN6-6WVU] (last visited Oct. 21, 2019); ChILD Welfare InFo. Gateway, Health-Care Coverage For Youth in Foster CARE-AND AFTER 1, 2-3 (2015), available at https:// www.childwelfare.gov/pubpdfs/health_care_foster.pdf [https:// perma.cc/47PT-48NU]; Makayla Palmer et al., Medicaid Managed Care $\mathcal{E}$ the Health Care Utilization of Foster Children, 54 INQUIRY: J. of Health Care Org., Provision, and Financing 1 (2017).

71. Stanton v. Bond, 504 F.2d 1246, 1247 (7th Cir. 1974); 42 U.S.C. $\S 1396 \mathrm{a}(\mathrm{a})(10)(\mathrm{A})(2019)$.

72. 42 U.S.C. $§ 1396 a(a)(43)(2019)$. 
provides for appropriate outreach and education, ${ }^{73}$ as well as systems to deliver EPSDT services to children. ${ }^{74}$ EPSDT places an affirmative duty on states to inform Medicaid recipients of the EPSDT services available and to arrange for appropriate treatments prescribed by their health care providers. ${ }^{75}$ As one court put it, "[t]hese EPSDT requirements differ from merely providing 'access' to services: the Medicaid statute places affirmative obligations on states to assure that these services are actually provided to Medicaid eligible children in a timely and effective manner." 76

EPSDT requires four specific categories of services screening, vision, dental and hearing services. ${ }^{77}$ EPSDT also requires "such other necessary health care, diagnostic services, treatment, and other measures described in $[\S 1396 \mathrm{~d}(\mathrm{a})]$ to correct or ameliorate defects and physical and mental illnesses and conditions discovered by the screening services, whether or not such services are covered under the State plan."78 Thus, EPSDT ensures that children have access to all optional and mandatory Medicaid services set forth in the Social Security Act, as well as any other services a state has chosen to make available under its state plan. ${ }^{79}$ The range of services delineated under the Social Security Act under 42 U.S.C. $\S 1396 d(a)$ is broad and

73. Wisconsin Welfare Rights Org. v. Newgent, 433 F. Supp. 204 (E.D. Wis. 1977).

74. Chisholm v. Hood, 110 F. Supp. 2d 499, 507-508 (E.D. La. 2000); Bond v. Stanton, 655 F.2d 766, 769 (7th Cir. 1981).

75. Mitchell v. Johnston, 701 F.2d 337, 347 (5th Cir. 1983) (citing 42 U.S.C. $\S 603(\mathrm{~g})$ ) (explaining that the statute was added by Congress to Title XIX in 1972 in response to concern that participating states were refusing to adequately ensure that eligible children know of and obtained services provided under law); Pediatric Specialty Care, Inc. v. Ark. Human Services, 293 F.3d 472, 478 (8th Cir. 2002) (citing 42 U.S.C. $§ 1396 a(43)$ ); J.E. v. Wong, No. 14-00399, 2016 WL 4275590, at*15 (D. Haw. Aug. 12, 2016).

76. Memisovski ex rel. Memisovski v. Maram, No. 92 C 1982, 2004 WL 1878332, at *50 (N.D. Ill. Aug. 23, 2004).

77. 42 U.S.C. $\S 1396 \mathrm{~d}(\mathrm{r})(1)(\mathrm{B})(2019)$.

78. K.G. ex rel. Garrido v. Dudek, 981 F. Supp. 2d 1275, 1276 (S.D. Fla. 2013).

79. EPSDT Guide For States, supra note 4, at 9-10. 
inclusive of essentially all types of medical care and treatment. ${ }^{80}$ While states have the option to provide many of the services provided for in $\$ 1396 \mathrm{~d}(\mathrm{a})$ to adult eligible populations, states

80. Medicaid Services included in $§ 1396(\mathrm{a})$ :

(1) inpatient hospital services;

(2) outpatient hospital services;

(3) laboratory and x-ray services;

(4) nursing facility services, EPSDT services, family planning services, counseling and pharmacotherapy services for cessation of tobacco use for pregnant women;

(5) physicians' services (in the office, home, hospital, nursing facility, or elsewhere);

(6) medical care;

(7) home health services;

(8) private duty nursing services;

(9) clinical services;

(10) dental services;

(11) physical therapy and related services;

(12) prescribed drugs, dentures, prosthetic devices, eyeglasses;

(13) other diagnostic, screening, preventative, and rehabilitative services;

(14) inpatient hospital services for individuals over 65 with a mental disease;

(15) services in an intermediate care facility for the mentally retarded;

(16) inpatient psychiatric hospital services for those under 21;

(17) nurse mid-wife services;

(18) hospice care;

(19) case management services;

(20) respiratory care services;

(21) services furnished by a certified pediatric nurse practitioner or certified family nurse practitioner;

(22) home and community care;

(23) community supported living arrangements services;

(24) personal care services;

(25) primary care case management services;

(26) services furnished under a PACE program;

(27) primary and secondary medical strategies and treatment and services for individuals who have Sickle Cell Disease;

(28) freestanding birth center services; and

(29) any other medical care, and any other type of remedial care recognized under State law.

42 U.S.C. $\S 1396(a)(1)-(29)$ (2019); See 42 U.S.C. $\S \S 1396 d(a)(1)-$ (5) (2019) (providing mandatory services for all Medicaid recipients include inpatient hospital services, outpatient hospital, laboratory and x-ray services); 42 C.F.R. §§ 457.1, 457.402 (2018). 
must provide every listed services to EPSDT eligible young people when medically necessary. ${ }^{81}$

Additionally, EPSDT mandates early and periodic screening services to ensure a preventive approach to child health care, another variation from traditional Medicaid programming for adults. $^{82}$ Early and periodic screening services facilitate the identification of children with medical conditions, developmental delays, health issues, and risks for developing delays or medical issues, including mental health conditions, as early as possible. ${ }^{83}$ This facilitates appropriate diagnostic testing and treatment before a condition emerges, becomes worse, or becomes debilitating for a child. ${ }^{84}$ EPSDT screening services must be provided "both at established times and on an as-needed basis." 85 States must develop periodicity schedules, for example regular well-baby visits and annual well-child visits, in consultation with medical and dental associations. ${ }^{86}$ Many states use the American Academy of Pediatrics Bright Futures guidelines, discussed further below in Part III, as a basis for their periodicity schedules. ${ }^{87}$ However, if a health, developmental, or educational professional suggests that a child needs a screening outside of the schedule, supplemental screening services must also be covered without prior authorization. ${ }^{88}$ If further diagnostic testing or

81. EPSDT GUIDE FOR STATES, supra note 4, at 10.

82. Ekloff v. Rodgers, 443 F. Supp. 2d 1173, 1178-1179, 1181 (D. Ariz. 2006); Paul H. Wise, The Transformation of Child Health in the United States, 23 Health AfF. 9, 20-21 (2004); See N. Halfon \& M. Hochstein, Life Course Health Development: An Integrated Framework for Developing Health, Policy, and Research, 80 Milbank Q. 433 (2002); NAT'L Res. Council Inst. of Med., From Neurons to NeIghborhoods 337-338, 400 (Jack P. Shonkoff \& Deborah A. Phillips eds. 2000); E. L. Schor et al., Medicaid: Health Promotion and Disease Prevention for School Readiness, 26 HeALTh AFF. 420-29 (2007); EPSDT at Forty, supra note 58, at 4.

83. EPSDT at Forty, supra note 58, at 4.

84. Id.

85. $I d$.

86. $I d$.

87. See discussion at Part III, infra; EPSDT GuIDE FOR STATEs, supra note 4 , at 4 .

88. Id. 
medical services and treatment are indicated by any screening, those services must be provided as well. ${ }^{89}$

EPSDT is unique in its preventive focus and in its expansive definition of medical necessity, which includes services that both correct and ameliorate a medical condition..${ }^{90}$ According to CMS, ameliorate means to "make more tolerable." 91 Services that ameliorate a medical condition are an important part of EPSDT because of their ability to "prevent conditions from worsening, reduce pain, and avert the development of more costly illnesses and conditions." 92 This is a broad coverage requirement, and includes less common medical items such as decubitus cushions, ${ }^{93}$ bed rails, ${ }^{94}$ incontinence supplies, ${ }^{95}$ and specially adapted devices like car seats. ${ }^{96}$ Further, rehabilitative and habilitative services are both covered by EPSDT,${ }^{97}$ including specialized and intensive behavioral health therapies (such as therapeutic behavioral services $^{98}$ and applied behavior analysis ${ }^{99}$ ) and do not have to cure or restore a condition, as is required for Medicaid-eligible adults to receive such services. ${ }^{100}$ Other services provided through EPSDT include wraparound care coordination and intensive in-

89. EPSDT at Forty, supra note 58, at 6.

90. K.G. ex rel. Garrido v. Dudek, 731 F.3d 1152, 1154 (11th Cir. 2013) (citing 42 U.S.C. $\S \S 1396 d(r)(1)-(5)$ ).

91. EPSDT GUIDE FOR STATES, supra note 4, at 10.

92. $I d$.

93. $I d$.

94. Id.

95. Smith ex rel. Smith v. Benson, 703 F. Supp. 2d 1262, 1277 (S. D. Fla. 2010); Ekloff v. Rodgers, 443 F. Supp. 2d 1173, 1181-1182 (D. Ariz. 2006).

96. EPSDT Guide FOR STATES, supra note 4, at 16.

97. A.M.T. v. Gargano, 781 F. Supp. 2d 798, 808 (S.D. Ind. 2011).

98. Emily Q. v. Bonta, 208 F. Supp. 2d 1078, 1090 (C.D. Cal. 2001).

99. Garrido v. Interim Sec'y, 731 F.3d 1152 (11th Cir. 2013) (vacating in part and remanding); K.G. ex rel. Garrido v. Dudek, 864 F. Supp. 2d 1314 (S.D. Fla. 2012).

100. EPSDT Guide FOR States, supra note 4, at 5, 11 (citing CMS State Medicaid ManUaL $\S 5124$.B). 
home services. ${ }^{101}$ Glasses, hearing aids, cochlear implants, and augmentative communication devices, ${ }^{102}$ in addition to vision and hearing screenings, are also covered. ${ }^{103}$

EPSDT effectively addresses access to care issues by mandating transportation and other supports to facilitate care in the community, away from home, and in schools. ${ }^{104}$ Scheduling support must be offered and transportation to and from appointments must be covered. This includes travel expenses like meals and lodging for a child and a caregiver if the child is being accompanied to a medically necessary appointment in location away from home. ${ }^{105}$ Though interpreters are not qualified providers under Medicaid, medical providers must provide interpreters under Title VI of the Civil Rights Act, the Americans with Disabilities Act, and the Affordable Care Act. ${ }^{106}$ Medical providers can bill for interpreter services alongside the Medicaid covered service. ${ }^{107}$ Further, Medicaid covered services provided as part of a child's Individualized Education Program under the Individuals with Disabilities Education Improvement Act may be billed to Medicaid under the Medicaid in Schools Act. ${ }^{108}$ Medicaid covered services "may be provided in, and reimbursed to,

101. Id. at 12 ("A number of home and community-based services, including those that can be provided through EPSDT, have proven to significantly enhance positive outcomes for children and youth. These include intensive care coordination ("wraparound"), intensive in-home services, and mobile crisis response and stabilization.").

102. Id. at 15; See Hunter v. Chiles, 944 F. Supp. 914, 922 (S.D. Fla. 1996) (emphasizing that the state is responsible for coverage of augmentative communication device under EPSDT despite state speculation school districts or other parties are responsible for coverage).

103. EPSDT GUIDE FOR StATES, supra note 4 , at 15 .

104. See 42 C.F.R. $\S 441.62$ (2018).

105. 42 U.S.C. $\S 1905(a)(29)$ (2018); See 42 C.F.R. $\S \S 440.170,441.62$ (2018).

106. See 45 C.F.R. § 80.1 (2018); See 42 U.S.C.S. § 12182 (2018) (prohibiting discrimination under the Americans with Disabilities Act); See 45 C.F.R. $\S 92.1$ (2018).

107. EPSDT Guide For States, supra note 4, at 18.

108. Id. at 20-21; 42 C.F.R. § 431.107 (2018). 
schools," including physical therapy, occupational therapy, and speech therapy. ${ }^{109}$ Thus, Medicaid is a broad reaching and critically important program for children's health and particularly for children with disabilities and chronic health challenges.

EPSDT requires states to educate recipients regarding the services available under EPSDT and engage in outreach and coordination of care. ${ }^{110}$ In the first major EPSDT case, Stanton $v$. Bond, the Seventh Circuit heavily criticized Indiana's early failures to establish an adequate EPSDT program and its assertion that it was in compliance with EPSDT because families could seek EPSDT services from local health care providers. ${ }^{11}$ The court determined that "Indiana's somewhat casual approach to EPSDT hardly conforms to the aggressive search for early detection of child health problems envisaged by Congress." 112 The court further explained that "EPSDT programs must be brought to the recipients; the recipients will not ordinarily go to the programs until it is too late to accomplish the congressional purpose."113 This decision reiterates Congress's intention that state EPSDT programs reach beyond simply making health care available and that they take affirmative steps to reach out to Medicaid-eligible children and ensure that they receive the broad preventive care and treatment available.

Since Stanton, Courts have consistently upheld a state's obligations to implement the broad coverage requirements of EPSDT. As the Fifth Circuit noted in S.D. ex rel. Dickson v. Hood, "[e]very Circuit which has examined the scope of the EPSDT program has recognized that states must cover every type of health care or service necessary for EPSDT corrective or ameliorative purposes that is allowable under $1396 \mathrm{~d}(\mathrm{a}) . "{ }^{114}$ Courts have affirmed that EPSDT mandates coverage for early

109. EPSDT Guide FOR STATES, supra note 4, at 21.

110. Stanton v. Bond, 504 F.2d 1246, 1250 (7th Cir. 1974); John B. v. Menke, 176 F. Supp. 2d 786, 792 (M.D. Tenn. 2001).

111. Stanton, 504 F.2d at $1250-51$.

112. Id. at 1251.

113. $I d$.

114. S.D. ex rel. Dickson v. Hood, 391 F.3d 581, 590 (5th Cir. 2004) (citing Collins v. Hamilton, 349 F.3d 371, 376 (7th Cir. 2003)). 
intervention services, ${ }^{115}$ organ transplants, ${ }^{116}$ Applied Behavioral Analysis (ABA) therapy for children with autism, ${ }^{117}$ incontinence supplies, ${ }^{118}$ regular periodic dental care, ${ }^{119}$ mental health care ${ }^{120}$ augmentative communication devices, ${ }^{121}$ maintenance therapies, ${ }^{122}$ and transgender services. ${ }^{123}$ While courts have generally extended EPSDT coverage for medically necessary - and often life-saving or life-altering - care for children, state efforts to balance costs in this time of constant medical advancement has created ongoing challenges as patients and providers push for the extension of EPSDT to innovative and often costly medical services, pharmaceuticals, and medical equipment. ${ }^{124}$

\section{B. Medical Advancements}

While EPSDT's coverage mandates are broad and comprehensive, there are exceptions. Medicaid plans are not required to cover services that are non-medical in nature, experimental, or not an accepted method of medical practice or treatment. $^{125}$ These exceptions provide guidance, yet simultaneously present moving targets as standards of practice in medical care change rapidly. ${ }^{126}$ Medical procedures may transition

115. Pediatric Specialty Care, Inc. v. Arkansas Dept. of Human Serv., 364 F.3d 925, 932 (8th Cir. 2004).

116. Perieira by Perieira v. Kozlowski, 996 F.2d 723, 727 (4th Cir. 1993); Pittman ex rel. Pope v. Sec'y Florida Dept. of Health, 998 F.2d 887 (11th Cir. 1993).

117. K.G. ex rel. Garrido v. Dudek, 731 F.3d 1152, 1159 (11th Cir. 2013).

118. S.D. v. Hood, 391 F.3d at 602 .

119. Mitchell v. Johnston, 701 F.2d 337, 343 (5th Cir. 1983).

120. S.D. v. Hood, 391 F.3d at 586, 593.

121. Hunter v. Chiles, 944 F. Supp. 914, 922 (S.D. Fla. 1996).

122. A.M.T. v. Gargano, 781 F. Supp. 2d 798, 808 (S.D. Ind. 2011).

123. Cruz v. Zucker, 195 F. Supp. 3d 554, 581-582 (S.D.N.Y. 2016) withdrawn, Cruz v. Zucker, 16-4173, 2017 WL 6506587, at*1 (2d Cir. 2017).

124. Perkins \& Agrawal, supra note 7, at S245.

125. EPSDT GUIDE FOR STATES, supra note 4, at 24.

126. Perkins \& Agrawal, supra note 7, at S247-48. 
from experimental to standard practice before plan guidance and policies have been updated. Pediatricians treating medically complex patients or patients with rare conditions, for example, face particular challenges in showing that new or alternative treatments are effective and clinically proven for children or for treatment of the specific rare condition. ${ }^{127}$ Approximately twothirds of medically complex children in the United States are Medicaid recipients. ${ }^{128}$ These children are expensive to care for and "payers are increasingly using assessment tools with unclear validity to supersede personal physician judgment in determination of medical necessity or services such as home nursing case." ${ }^{129}$ However, at its core, EPSDT requires that even medically complex children receive the care and treatment necessary to correct or ameliorate any health condition regardless of cost.

Further, Medicaid requires that state plans ensure equity in care among Medicaid recipients by employing methods and practices "so that care and services are available under the plan at least to the extent that such care and services are available to the general population in the geographic area."'130 Because Medicaid plans determine appropriate standards of medical care, ensuring equity in access between Medicaid-eligible children and children in the general population requires consideration of how advancements in care and shifts in coverage develop for children on private insurance so that Medicaid-eligible children are not receiving different care than their privately insured counterparts.

According to national EPSDT expert Jane Perkins and her co-author Rishi Agrawal, "[d]ata from the National Survey of Children with Special Health Care Needs suggest that approximately half of families of more complex children with

127. Id.

128. Id. at $\mathrm{S} 243$.

129. Id. (citing Jane Perkins, Ensuring that Assessment Tools Are Available to Enrollees, NAT'L HeAlth L. Program, https:// healthlaw.org/resource/ensuring-that-assessment-tools-areavailable-to-enrollees/ [https://perma.cc/9XNE-2LFV] (last visited Mar. 5, 2019).

130. Pediatric Specialty Care, Inc. v. Arkansas Dept. of Human Serv., 364 F.3d 925, 930-31 (8th Cir. 2004) (holding that this section applies not only to the rate of payment for medical care but also to the method and process of payment of services). 
special health care needs experience unmet medical needs, financial problems, and reduced employment related to their children's conditions." 131 The impact of inadequate care is thus significant for children and their families.

EPSDT was intended to support and ensure adequate care to vulnerable children. However, as medical advancements emerge and the correlating costs of health care have risen, states continue to struggle to maintain costs while growing their Medicaid plans and ensuring adequate EPSDT coverage for children with significant health care needs. This struggle has been exemplified in the way that many states have handled medical advancements such as transplants, ABA therapy for children with autism, and intensive advanced mental health therapies for children with severe mental and emotional health needs.

\section{Transplants}

In 1993, three federal circuits considered whether heart and liver-bowel transplants were covered under EPSDT. ${ }^{132}$ All three determined that transplants are a mandatory covered service for children under EPSDT, even though transplant coverage is optional for adults under Medicaid. In Miller by Miller $v$. Whitburn, the Seventh Circuit grappled with whether a liverbowel transplant prescribed for five-year-old Tiffany Miller was experimental as asserted by the Secretary of the Wisconsin Department of Health and Social Services. ${ }^{133}$ The Court adopted a Fifth Circuit definition of experimental:

... whether the service has come to be generally accepted by the professional medical community as an effective and proven treatment for the condition for which it is being used. If it is Medicare may make a payment. On the other hand, if the service is rarely used, novel or relatively unknown, then authoritative evidence must be obtained

131. Perkins \& Agrawal, supra note 7, at S243 (citing D. Z. Kuo et al., A National Profile of Caregiver Challenges Among More Medically Complex Children with Special Health Care Needs, 165 ARCHIVAL Pediatric Adolescent Med. 1020-26 (2011)).

132. Miller by Miller v. Whitburn, 10 F.3d 1315, 1316 (7th Cir. 1993); Perieira by Pereira v. Kozlowski, 996 F.2d 723, 727 (4th Cir. 1993); Pittman by Pope v. Secretary, 998 F.2d 887 (11th Cir. 1993).

133. Miller v. Whitburn, 10 F.3d at 1317. 
The Promise and Failures of Children's Medicaid and the Role of Medical-Legal Partnerships as Monitors and Advocates

that it is safe and effective before Medicaid may make a payment. ${ }^{134}$

The court further indicated that

different definitions of 'experimental' may be necessary depending upon the notoriety of the treatment under review. Indeed, certain procedures may be so new and, as a result, relatively unknown, that the medical community may not yet have formed an opinion as to their efficacy. We agree with the court in Rush that such procedures are not per se experimental. If 'authoritative evidence' exists that attests to a procedure's safety and effectiveness, it is not 'experimental.' 135

Miller provides important guidance on how states should consider medical advancements and how new procedures evolve from experimental to accepted standards of care among the medical profession. As medical advancements continue, these determinations will continue to fall upon states and will significantly impact access to care for Medicaid-eligible children.

\section{ABA Therapy}

Another example of conflicts over state EPSDT coverage for medical advancements or new treatments relates to developments in therapy for children diagnosed with autism spectrum disorder. As autism became a more prevalent diagnosis for children, new treatments were recognized and developed. ABA, developed in

134. Id. at 1320 (citing Rush v. Parham, 625 F.2d 1150, 1156 (5th Cir. 1980)).

135. Id. (citing Maxwell J. Mehlman, Health Care Cost Containment and Medicaid Technology: A Critique of Waste Theory, 36 CASE W. RES. L. REV 778, 785 (1986)) (explaining that "[t]he effectiveness of a procedure may be ascertained by considering such factors, among others, as: (1) the mortality of patients over the period in which the procedure has been performed; (2) how often it has been performed, and how successful it has been; (3) the reputation of the doctors and medical centers performing the procedure, and their record in related areas; (4) the long-term prognosis of patients who had had the procedure performed on them and (5) the extent to which medical science in related areas has developed rapidly."). 
the late 1950 s and 1960 s, ${ }^{136}$ is a treatment now commonly used for children diagnosed with autism spectrum disorder (ASD). First used to treat autism in 1987, ${ }^{137}$ and commonly prescribed since the 2000s, ${ }^{138}$ "ABA is a type of early intensive behavioral interaction health service that uses a structured one-on-one program to treat the behavioral problems associated with ASD." ${ }^{139}$ As ABA became an accepted treatment for children with ASD, states struggled to keep up with this new therapy through EPSDT plan coverage and related policies. Litigation emerged in many states regarding access to ABA for Medicaid-eligible children in the 2010's. ${ }^{140}$ Florida initially refused to cover ABA therapy, indicating that it was experimental and therefore not medically necessary. ${ }^{141}$ Similarly, Hawaii's Medicaid administrator indicated in 2013 that ABA therapy would not be covered by the State's Medicaid plan because it was not "evidence[ ]-based and, therefore, not medically necessary." ${ }^{142}$

136. Dennis R. Dixon et al., A Brief History of Functional Analysis and Applied Behavioral Analysis, in FunCTIONAL ASSESSMENT FOR Challenging Behaviors, Autism and Child Psychopathology SERIES 3, 6 (J.L. Matson ed., 2012).

137. Lisa Jo Rudy, What is ABA (Applied Behavioral Analysis) Therapy for Autism? ABA Can Teach Skills and Change Behaviors, VERYwell HEAlth (Aug. 31, 2018), https://www.verywellhealth .com/aba-applied-behavioral-analysis-therapy-autism-259913 [https://perma.cc/8SBU-HCWK].

138. Scott M. Myers \& Chris P. Johnson, Management of Children with Autism Spectrum Disorders, 120 AM. ACAD. PediATRICs 1162, 1164 (2007).

139. K.G. ex rel. Garrido v. Dudek, 731 F.3d 1152, 1155 (11th Cir. 2013).

140. See, e.g., id.; Chisolm v. Kliebert, No. 97-3274, 2013 WL 3807990 (E.D. La. 2013); Chisholm on Behalf of CC v. Gee, No. 97-3274, 2017 WL 3730514 (E.D. La. Aug. 30, 2017); J.E. v. Wong, No. 1400399, 2016 WL 4275590 (D. Haw. Aug. 12, 2016); Disability L. Ctr. of Alaska v. Davidson, No. 3:16-cv-02770-HRH, 2018 WL 1528158, at *5 (D. Alaska 2018); See generally Parents League for Effective Autism Serv's v. Jones-Kelley, 565 F. Supp. 2d 905 (S.D. Ohio 2008) (affirmed by 339 Fed. App'x 542 (6th Cir. 2009)).

141. Garrido, 731 F.3d at 1155-56; K.G. ex rel. Garrido v. Dudek, 864 F. Supp. 2d 1314, 1316 (S.D. Fla. 2012).

142. Wong, 2016 WL 4275590 , at $* 3$. 
In 2014, as states were grappling with whether to cover ABA therapy, CMS issued an information bulletin indicating that CMS was not mandating coverage for ABA treatment, but rather indicating that ABA treatment "is one treatment modality for ASD. CMS is not endorsing or requiring any particular treatment modality for ASD. State Medicaid agencies are responsible for determining what services are medically necessary for eligible individuals." 143 Several court decisions track the process of adding ABA therapy to state EPSDT plan coverage as ABA therapy became a widely accepted treatment for autism.

In J.E. v. Wong, the U.S. District Court for Hawaii outlined how the state Medicaid program transitioned from denying ABA therapy as an evidence-based treatment in January 2013, to August 2014 when the Medicaid director acknowledged that ABA treatment is evidence-based and may qualify as medically necessary under Medicaid, to August 2015 when the state issued a memorandum to its Medicaid managed health plans indicating ABA therapy was an EPSDT covered service. ${ }^{144}$ The court held that Hawaii's Medicaid program delayed creating a policy on ABA coverage and further that the program failed to notify EPSDT recipients of the change in coverage and availability of ABA therapy. ${ }^{145}$ Alaska similarly took several years from when it acknowledged that it should provide ABA therapy in 2014 to the development of policies and Medicaid-plan amendments to provide for ABA coverage under EPSDT in 2018. ${ }^{146}$

These cases revealing delays in extending ABA coverage to children with autism raise questions about how efficiently states change Medicaid policies as medical advancements and standard treatments change. They also raise issues under EPSDT and Medicaid's mandate that medical assistance be provided with reasonable promptness, ${ }^{147}$ "Medicaid regulations provide that a state agency must '[f] urnish Medicaid promptly to beneficiaries without any delay caused by the agency's administrative

143. Id. at $* 5$.

144. Id. at $* 3, * 6$.

145. Id. at $* 18$.

146. Disability L. Ctr. of Alaska v. Davidson, No. 3:16-cv-02770-HRH, 2018 WL 1528158, at *10 (D. Alaska 2018).

147. Id. at *7 (citing Katie A. v. L.A. County, 481 F.3d 1150, 1159 (9th Cir. 2006) (citing 42 U.S.C. § 1396a(a)(8))). 
procedures[.]"'148 Therefore, states are not only required to adjust their Medicaid plans and EPSDT coverage policies as medical advancements and standards of practice evolve, but they must do so in a timely manner so that children aren't suffering the potential life-long consequences of going without critical care at the most formative moments in their lives.

\section{Mental Health Treatment}

Mental health services are another critical component of the EPSDT program. Periodic EPSDT screenings should include mental health screenings, and treatment should include mental health care indicated by those screenings. ${ }^{149}$ A few states have been challenged for their insufficient mental health services under EPSDT. ${ }^{150}$ In Emily Q. v. Bonta, the United States District Court for the Central District of California considered whether the state of California had provided and informed Medicaid beneficiaries of a new mental health treatment called therapeutic behavioral services (TBS). ${ }^{151}$ TBS "involves having a trained, experienced staff person available on a one-on-one basis to work with a troubled child in his or her home and community."

148. Id. at ${ }^{*} 10$ (quoting 42 C.F.R. $\S 435.930(\mathrm{a})$ ).

149. Yael Cannon, A Mental Health Checkup for Children at the Doctor's Office: Lessons from the Medical-Legal Partnership Movement to Fulfill Medicaid's Promise, 17 Yale J. OF Health POL'Y, L., \& ETHICS 253, 256 (2017) (citing 42 U.S.C. $\S 1396 \mathrm{~d}(\mathrm{r})(1)(\mathrm{B})(2012))$; see 42 C.F.R. $\S 441.56(\mathrm{~b})(1)$ (2018).

150. Emily Q. v. Bonta, 208 F. Supp. 2d 1078, 1107 (C.D. Cal. 2001) (ordering the state to provide for a new, intensive therapeutic behavioral service to Medicaid-eligible children); Katie A. v. L.A. County, 481 F.3d at 1162-1163 (considering whether wraparound services and therapeutic foster-care services were mandatory under EPSDT, but determining that the services were "bundled services," thus holding that the question was whether medically necessary services were available (not whether they were bundled in a particular way), and finding that states have discretion in how to provide medically necessary services); S.R. v. Penn. Dep't of Human Serv's, 325 F.R.D. 103 (M.D. Penn. 2018) (approving class certification to plaintiffs challenging department policies and practices which allegedly failed to provide adequate mental health services).

151. Emily Q. v. Bonta, 208 F. Supp. 2d at 1083.

152. Id. at 1083 . 
TBS is provided to young people with "serious emotional problems" and is provided "to prevent placement in an institution or group home." 153

The Court found that the state, which had been previously ordered (through a preliminary injunction) to cover TBS, must provide notice to Medicaid beneficiaries about the availability of EPSDT services, including the availability of supplemental mental health services (such as TBS), as well as where and how to obtain them. ${ }^{154}$ The court further held that California must specifically inform Medicaid-eligible children who were being admitted to psychiatric hospitals, or any institution for mental disease, of the availability of $\mathrm{TBS}^{155}$ and provide compensatory TBS to beneficiaries who had been wrongly denied such services. ${ }^{156}$

Thus, courts have consistently found that EPSDT coverage for medical advancements extends to medical, developmental, and mental health related medical conditions. These decisions are consistent with the broad and comprehensive EPSDT coverage requirements set out and reinforced by Congress throughout the years.

\section{EPSDT Enforcement}

When state Medicaid programs fail to comply with EPSDT or fail to provide medically necessary care to eligible children, Medicaid beneficiaries have a variety of options to enforce their rights and compel coverage for the care they need. ${ }^{157}$

Medicaid-eligible children receiving coverage through Medicaid managed care organizations (MCOs) can appeal to the MCO directly to challenge coverage denials. ${ }^{158}$ The procedures and timelines for different plans may vary, but generally MCOs provide an appeal process that involves a paper review of their prior decision and consideration of new evidence submitted by the

153. Id. at 1102 .

154. Id. at $1096-97$

155. Id. at 1097 .

156. Id. at 1110.

157. See 42 U.S.C. § 1396a(a)(3) (2018).

158. See 42 C.F.R. § 438.402 (2018). 
beneficiary or their health care providers. ${ }^{159}$ If necessary, expedited appeals can be requested to ensure prompt review of denials for urgently needed care. ${ }^{160}$

In addition, Medicaid beneficiaries have the right to a state administrative appeal, or a "fair hearing," before the state Medicaid department or designated state agency or hearings bureau to challenge Medicaid coverage denials by state Medicaid plans or MCOs. ${ }^{161}$ The fair hearing provides beneficiaries an opportunity to present evidence and witnesses and cross examine the $\mathrm{MCO}$ or state Medicaid program medical directors or administrators regarding their decisions, policies, and procedures related to coverage denials. ${ }^{162}$ If these administrative-appeal efforts fail, beneficiaries can appeal Medicaid denials in state courts. ${ }^{163}$

As reflected in many of the cases discussed above, federal court action can also be filed under $\S 1983$ of the Civil Rights Act of $1871^{164}$ on behalf of individual Medicaid beneficiaries, a class of beneficiaries, or on behalf of organizational plaintiffs, to seek enforcement of EPSDT. According to Perkins and Agrawal:

[T]he courts have also played an important role in securing EPSDT benefits for Medicaid-enrolled children and youth, including those with medically complex conditions. Some of these cases have produced system-wide changes and, as such, were implemented over a period of months and years. ${ }^{165}$

Litigation on behalf of Medicaid-eligible children has been critically important in obtaining a wide array of medical care for children and in pushing states to implement appropriate EPSDT programs. These cases have helped to enforce the expansive preventive coverage required under EPSDT and have ensured

159. See 42 C.F.R. $\S 438.406$ (2018).

160. See 42 C.F.R. $\S 438.408$ (2018).

161. 42 C.F.R. $\S 431.205(b)$ (2018); Goldberg v. Kelly, 397 U.S. 254, 259-260 (1970).

162. Goldberg, 397 U.S. at 259-260.

163. Musumeci, supra note 40, at 21.

164. 42 U.S.C. $§ 1983$ (2018).

165. Perkins \& Agrawal, supra note 7, at S245. 
that new and effective treatments are made available to children with disabilities and complex medical conditions.

\section{Current Medicaid Landscape}

In an effort to address the rising costs of health care for Medicaid recipients, states have endeavored to control expenditures through state plan limitations and through the use of Medicaid MCOs. Over the past few decades, most states have been transitioning from traditional fee-for-service, or "straight Medicaid" state administered plans, to a privatized MCO model. ${ }^{166}$ This shift in service delivery was facilitated by "[i]ncreasing use of managed care in the private sector and easing of federal restrictions on the use of prepaid health plans in Medicaid." 167 While state use of MCOs began in the 1980s, the Balanced Budget Act of 1997 made it easier for states to utilize MCOs and even require MCO enrollment among beneficiaries. ${ }^{168}$ Currently, most states are using MCOs to provide Medicaid. ${ }^{169}$ Similarly, "[s]tates are . . rapidly expanding their use of MCOs to reach larger geographic areas, serve more medically complex beneficiaries, deliver long-term services and supports."170

Under the MCO model, states contract with private health insurance programs to administer Medicaid coverage to eligible children and adults. ${ }^{171}$ States use MCOs as a cost saving measure,

166. Mann et al., supra note 22, at 36; Lisa Axelrod, The Trend Toward Medicaid Managed Care: Is the Government Selling out the Medicaid Poor?, 7 B.U. PuB. InT. L. J. 251, 254 (1998).

167. Mann et al., supra note 22 , at 36 .

168. Id.

169. Total Medicaid MCOs, KAISER FAM. Found., https://www.kff.org/ medicaid/state-indicator/total-medicaid-mcos/ [https://perma.cc/ U6J6-R2XE] (last visited Feb. 24, 2019).

170. Medicaid Managed Care Market Tracker, KAISER FAM. Found., https://www.kff.org/data-collection/medicaid-managed-caremarket-tracker/ [https://perma.cc/QV4F-HSS6] (last visited Feb. 24, 2019) ("[S]tates that have expanded Medicaid under the Affordable Care Act (ACA) ... [now] serve millions of newly eligible low-income adults.").

171. See Jane Perkins \& Lourdes A. Rivera, EPSDT and Managed Care: Do Plans Know What They Are Getting Into?, 28 ClearInghouse REV. (1995). 
entrusting private insurance companies to maintain the legally mandated Medicaid coverage while cutting expenses. ${ }^{172}$ States pay MCOs a fixed amount per beneficiary and the MCO coordinates care and makes decisions regarding whether requested medical services are covered and/or medically necessary. ${ }^{173}$ This shift to MCOs has resulted in changes in EPSDT coverage for children, particularly for children with complex and chronic medical and mental health conditions. Under this coverage system, health care providers regularly encounter denials for medically necessary therapies, prescriptions, medical equipment, and life-saving monitoring devices. ${ }^{174}$ According to Lisa Axelrod, " $\left.\mathrm{t}\right]$ here is a fine line between managed care and mismanaged care - if MCOs eliminate coverage to too many services, Medicaid beneficiaries will be certain to pay the price with their health."175

After spending over a decade collaborating with medical providers, training them on the provisions of EPSDT, and advocating for expanded coverage for their child patients across three states, I have seen many common trends in the inefficiencies in various Medicaid programs and the harm to providers and patients. A denial of medical services and care can result in significant cost to young patients and their medical providers. Medicaid plan denials can result in extensive resource investment by health care providers who must spend time on paperwork and supplemental documentation in support of preauthorization requests as well as on advocacy on behalf of patients challenging coverage denials. For example, it is common for physicians to request peer-to-peer reviews with Medicaid plan medical directors when a preauthorization request is denied for a patient. ${ }^{176}$

172. Michael Sparer, Medicaid Managed Care: Costs, Access, \& Quality of Care 4 (Robert Wood Johnson Found. 2012).

173. See generally RAND Inst. For Civil Justice and Rand Health, Inside the BlaCK BoX of MANAged CARE DeCisions (2004).

174. I worked with a variety of pediatric health-care providers in Ohio and Michigan from 2008-2017 while those states transitioned to MCO coverage for medically complex children; providers reported significant changes in coverage decisions between state administered fee-for-service Medicaid plans and MCO plans.

175. Axelrod, supra note 166, at 256.

176. Denials / Appeals: What to Do When Your Insurance Company Denies Your Coverage, Juvenile Diabetes Res. Found., https://www.jdrf.org/t1d-resources/living-with-t1d/insurance/ 
Physicians and other health care providers also engage in MCO appeals and testify at state fair hearings on behalf of patients. ${ }^{177}$ As one could predict, this advocacy work is time consuming for providers. In addition, many states have several MCOs and each may have entirely different policies, forms, and procedures related to formularies, covered services, preauthorization requests, and administrative appeals, ${ }^{178}$ which cause even more confusion and soak up more provider time. According to Perkins and Agrawal:

As Medicaid beneficiaries are increasingly moved from feefor-service to managed care, accountable care organizations, and other risk-based payment structures, it is important to note that Medicaid beneficiaries entitled to EPSDT retain the rights to receive all medically necessary services. Courts have been called on to confirm that EPSDT's broad coverage and treatment requirements continue in full force and effect. Whether management is delegated to a third party, the state Medicaid agency remains responsible for ensuring that EPSDT is provided as the law intends. ${ }^{179}$

insurance-denials-appeals/ [https://perma.cc/8A4R-44B5] (last visited Oct. 20, 2018); see Make 'Peer to Peer' Happen Within 24 Hours or Face Denied Claim, Relias Media (Jan. 1, 2018), https://www.reliasmedia.com/articles/141921-make-peer-to-peerhappen-within-24-hours-or-face-denied-claim [https://perma.cc/ K2XS-GFHN] (explaining that the peer-to-peer review is a process through which the treating provider can consult with and attempt to convince the MCO medical director that the requested service is medically necessary and/or standard treatment for the condition for a patient).

177. 42 C.F.R. $\S 438.402(\mathrm{c})(1)(\mathrm{ii})$ (2018).

178. Medicare Managed Care Market Tracker, KaISER Fam. Found., https://www.kff.org/data-collection/medicaid-managed-caremarket-tracker/ [https://perma.cc/69CP-ZWWR] (last visited Oct. 29, 2019); see also MCO Qualification Guidelines, DisABILITY RTS. Educ. \& DEF. Fund (July 2004), https://dredf.org/wpcontent/uploads/2012/08/NY-MCO-guidelines.pdf

[https://perma.cc/HA4Y-CHFS] (providing an example of variations in New York's intrastate MCOs).

179. Perkins \& Agrawal, supra note 7, at S246 (citing K.C. ex rel. Africa H. v. Shipman, 716 F.3d 107, 119 (4th Cir. 2013)). 
Despite this mandate for all EPSDT insurers, navigating multiple Medicaid and MCO systems can cause confusion for providers because, while EPSDT requires consistent coverage to all Medicaid-eligible children, coverage inconsistencies among plans exist and providers are left to navigate the morass in an effort to get services for patients. ${ }^{180}$ All of these efforts to obtain services for patients take the time of doctors, social workers, nurses, and other members of the health care team; they also limit time for patient care. This makes the system of EPSDT care for children ultimately less efficient and interferes with the provision of the breadth or preventive care and treatment intended by the statute.

Medicaid denial trends can also result in alterations in health provider practice and thus in the quality of health care to patients. As medical providers cope with coverage trends for their patients, logically they begin to shift care recommendations based on what they anticipate the patients' insurance will cover or what the patient's family can afford to pay out of pocket, rather than on their own clinical judgment regarding the patient's medical needs. ${ }^{181}$ The tragic result of this shift is a lack of access to medically necessary care for vulnerable children. These concerns

180. U.S. Gov't. AcCountability Off., GAO-10-810, Medicaid Managed Care: CMS's Oversight of States' Rate Setting NEEDS IMPROVEMENT 9 (2010).

181. While collaborating with the pediatric-endocrinology clinic at the University of Michigan Medical Center, health care providers indicated to me that they provided different care to different children depending on their insurance and related coverage trends. For example, several MCOs were not covering continuous glucose monitors (CGMs) for children and providers had stopped submitting preauthorization requests for CGMs for children on those plans, even when the providers believed that a CGM was medically necessary, because they knew that it would not be covered. Similarly, in Ohio, durable medical-equipment providers indicated that they would not submit preauthorization requests for pediatric hospital beds because the state's reimbursement rate for the beds was well below cost and, therefore, not worth it. Medical providers indicated that they would recommend that parents place medically complex children on mattresses on the floor or that families' churches could fundraise for specialty beds that were not covered by the state's Medicaid plan. In my years working with pediatric providers across several states, these types of stories were common. See discussion at Part IV(C), infra. 
The Promise and Failures of Children's Medicaid and the Role of Medical-Legal Partnerships as Monitors and Advocates

demonstrate a failure of our Medicaid programs to meet mandated EPSDT requirements.

\section{Medical-Legal Partnerships as EPSDT Monitors AND Advocates}

Lawyers have been engaged in EPSDT implementation and monitoring since its inception, utilizing policy advocacy, impact litigation, and individual client advocacy in the form of Medicaid appeals and other related litigation efforts. ${ }^{182}$ Physicians and other health care providers have similarly been engaged in advocacy to ensure that their patients receive necessary medical care. ${ }^{183}$ Health care providers spend countless hours conducting peer-to-peer reviews with $\mathrm{MCO}$ physicians in an effort to convince them that a recommended service is necessary, filing appeals on behalf of patients, and searching for alternative resources to cover health care expenses while children's hospitals lose millions of dollars annually on uncovered, life-saving care for Medicaid-eligible children. ${ }^{184} \mathrm{~A}$ concerted collaborative effort among lawyers and health care providers to identify EPSDT implementation issues and advocate for appropriate review and coverage standards, known as a medical-legal partnership (MLP), has the potential to hold Medicaid plans accountable to federal law and is critical to ensuring that Medicaid-eligible children receive the care they need.

MLPs present a unique framework for engaging in this collaborative interdisciplinary advocacy because they embed professional patient advocates in the medical team. MLPs integrate lawyers and paralegals alongside health care teams to detect, address and prevent health-harming social conditions for

182. Perkins, supra note 67.

183. Perkins \& Agrawal, supra note 7, S247-48.

184. See Am. Health Ass'n, Uncompensated Hospital Care Cost FACT SHEET (2017), available at https://www.aha.org/system/ files/2018-01/2017-uncompensated-care-factsheet.pdf [https:// perma.cc/C8G4-FS8Y]; Jeffrey Colvin, Financial Loss for Inpatient Care of Medicaid-Insured Children, 11 JAMA PEDIATRICS 1055, 1058-1061 (2016). 
people and communities. ${ }^{185}$ Under the MLP model, health care providers learn to screen patients for health-harming legal needs and refer them to legal partners. ${ }^{186}$ MLPs utilize an "integrated approach to health and legal services that facilitates critical, efficient, shared problem solving among health and legal teams who care for patients with complex health and legal needs." 187 MLPs typically provide training for health care providers on relevant laws, methods for identifying legal needs, and guidance for patient advocacy. ${ }^{188}$ They also offer on-site legal consultations and direct representation to patients and provide opportunities for collaborative upstream systemic advocacy. ${ }^{189}$ This model lends itself uniquely to the identification of EPSDT concerns and collaborative advocacy for EPSDT compliance.

\section{A. Medical-Legal Partnerships as Leaders in Patient Advocacy}

The medical and legal professions each present long histories of serving the poor and advocating on issues of social justice. ${ }^{190}$ The MLP model has provided these sometimes-dueling professions a framework for collaborative efforts to improve the health and wellbeing of disenfranchised patients and impoverished clients, which improves the systems with which they interact and strengthens the communities in which they live. This framework consists of: (1) training medical staff on how to

185. The Response, NAT'L CTR. FOR MED. L. P'SHIP, http://medicallegalpartnership.org/mlp-response/ LA2Q] (last visited Feb. 24, 2019).

[https://perma.cc/Q6KZ-

186. Elizabeth Tobin Tyler, Aligning Public Health, Health Care, Law and Policy, 8 J. Health \& Biomedical L. 211, 235 (2012).

187. Edward Paul et al., Medical-Legal Partnerships: Addressing Competency Needs Through Lawyers, 1 J. GRAduATE MED. EduC., 304, 306 (2009).

188. Bharath Krishnamurthy et al., What We Know and Need to Know About Medical-Legal Partnership, 67 S. C. L. REV. 377, 381 (2015).

189. Id. at 379 .

190. Russell Pearce, Lawyer and Public Service, The Historical Perspectives on Pro Bono Lawyering, 9 Am. U. J. Gender Soc. POL'Y \& L. 171, 176 (2001); Jaro Kotalik, Caring for the Poor What Can One Doctor Do?, 6 AMA J. OF ETHICS 392, 393 (2004); Jonathan Gruber \& David Rodriguez, How Much Uncompensated Care Do Doctors Provide?, 26 J. of Health ECON. 1151, 1153 (2007). 
identify health-harming legal needs; (2) treating the identified legal needs through legal interventions; (3) transforming clinical practice to treat social issues affecting health and well-being; and (4) improving population health by using interdisciplinary tools to achieve systemic change. ${ }^{191}$ The MLP model emerged over twenty years ago and has evolved and grown into an international movement of collaborative interdisciplinary change-making. ${ }^{192}$

In 1993, Dr. Barry Zuckerman, a pediatrician at Boston Medical Center, created the Family Advocacy Project, the first pilot MLP, to address the social factors that were influencing the health of his pediatric patients living in poverty. ${ }^{193}$ Seven years later, the Boston Medical Center received a 2.7-million-dollar grant to replicate the program throughout the United States. ${ }^{194}$ As the model spread, it also gained support from national professional organizations of doctors and lawyers including the American Bar Association and the American Medical Association, both of which passed resolutions supporting further development of MLPs. ${ }^{195}$ The MLP model has grown over time to include 167

191. Krishnamurthy et al., supra note 188 , at 379 .

192. Rebecca Huston et al., Medical-Legal Partnerships, 13 AMA J. OF EтHICS 555, 556 (2011); See Ellen Lawton, A History of the Medical-Legal Partnership Movement, Community Health Forum (Fall/Winter 2014), https://medical-legalpartnership.org/wpcontent/uploads/2015/01/NACHC-Magazine-A-History-of-theMedical-Legal-Partnership-Movement.pdf [https://perma.cc/3SB3 -EUGJ].

193. Elizabeth Tobin-Tyler, Allies Not Adversaries: Teaching Collaboration to the Next Generations of Doctors and Lawyers to Address Social Inequality, 11 J. HeAlth CARE L. \& POL'Y 249, 25051 (2008).

194. Id. at 251 .

195. Am. Bar Ass'n, Health Section Report to the House of DeleGates, H. of Del.-120A, at 2 (Va. 2007) ("The purpose of this recommendation is to encourage closer and more frequent collaboration between these professional communities in a truly holistic approach to health and well-being. Specifically, it seeks to promote 'medical-legal partnerships,' in which lawyers work with health care providers to identify and resolve legal issues affecting patients' health and well-being."); AMA Passes Resolution in Support of Medical-Legal Partnership, NAT'L CTR. FOR MED. L. P'SHIP (July 17, 2010), http://www.bostonbar.org/pub/bw/ 0910/062810/AMA_Press_Release.pdf [https://perma.cc/Y8LPLPWC] ("Resolution 7 (I-09) acknowledges that unmet legal needs 
legal aid agencies and 58 law schools, which provide legal support to patients at 442 health organizations in 48 states, all operating with coordination and support from the National Center for Medical-Legal Partnership. ${ }^{196}$

Now more than ever, MLPs have the potential for wideranging impact on health inequities and social justice. The ACA, passed in 2010, in addition to providing expanded Medicaid and private health insurance coverage, ${ }^{197}$ also called for a paradigm shift in the provision of health care to a more outcome-based preventative-care model. ${ }^{198}$ This model encourages innovative approaches to achieving improved community health, ${ }^{199}$ and thus enhanced interdisciplinary social justice initiatives. In a recent article, the directors of the National Center for MLP and colleagues expressed that " $\mathrm{i}] \mathrm{t}$ is in this dynamic transformational context that the medical-legal partnership approach has emerged as a leading intervention designed to address this health care conundrum." 200 As our views about what makes health care effective change and our health systems evolve along with them, the critical roles that other disciplines can play in improving health and well-being become more and more obvious. The MLP model, which brings social justice lawyers into the health care system, offers opportunities for pushing systems forward for vulnerable patients and clients. This model provides unique opportunities for the identification of preventive and health access related legal needs, such as EPSDT implementation, and for the practice of upstream advocacy, or systems change, to ensure that systems are functioning pursuant to the law and championing the public good.

have a significant impact on patient health and well-being, and that MLP, which integrates legal services in clinical settings, is an effective way to identify and resolve these problems.").

196. The Partnerships, NAT'L CTR. FOR MED. L. P'SHIP, https:// medical-legalpartnership.org/partnerships/ [https://perma.cc/ WV48-DXSA] (last visited Mar. 9, 2020).

197. 42 U.S.C. $§ 18051$ (2018) (expanding Medicaid); 42 U.S.C § 13031 (2018) (expanding private insurance).

198. Krishnamurthy et al., supra note 188, 385-386.

199. Id. at 378 .

200. Id. 
Health Matrix · Volume $30 \cdot 2020$

The Promise and Failures of Children's Medicaid and the Role of Medical-Legal Partnerships as Monitors and Advocates

\section{B. The MLP Model and Opportunities for Upstream Systems Change}

According to Ellen Lawton and Megan Sandel, "[t]he MLP approach to health is designed as an integrated, upstream effort among the health care, public health, and legal sectors that collectively work to improve social conditions for people and communities." ${ }^{201}$ MLPs provide a framework for systemic change through naturally flowing opportunities to observe and identify systemic failures. Because health care providers offer an essential resource for a wide cross-section of communities -including vulnerable populations - health care settings are a prime location for identifying preventive health-harming legal needs. In the course of identifying and meeting patients' legal care needs, legal partners within an MLP can move beyond direct-service case work by recognizing that individual cases "serve as diagnostic tools for failed policies." ${ }^{202}$ MLP lawyers and scholars have used these diagnostic tools and built upon health and public health concepts to develop a kind of "upstream advocacy," which leads to systemic and impactful work. ${ }^{203}$

Interdisciplinary teams of lawyers and doctors working in MLPs have successfully identified and addressed a number of systemic, health related social-justice issues that are ripe for upstream advocacy. For example, the Cincinnati Child HealthLaw Partnerships (Child HeLP), a partnership between the Legal Aid Society of Greater Cincinnati and Cincinnati Children's Hospital Medicaid Center, identified a pattern of housingcondition referrals stemming from properties owned by the same developer. ${ }^{204}$ The issues included but were not limited to: pests,

201. Id. at 379 (citing Ellen M. Lawton \& Megan Sandel, Medical-Legal Partnerships: Collaborating to Transform Healthcare for Vulnerable Patients: A Symposium Introduction and Overview, 35 J. L. MED. 1 (2014)).

202. Id. at 386 .

203. See generally David R. Williams et al., Moving Upstream: How Interventions that Address the Social Determinants of Health Can Improve Health and Reduce Disparities, 14 J. Pub. Health Mgt. PRAC. S8 (2008).

204. Andrew F. Beck et al., Identifying and Treating a Substandard Housing Cluster Using a Medical-Legal Partnership, 130 Pediatrics 831, 832 (2012). 
water damage, inadequate ventilation, peeling paint, broken windows, etc. ${ }^{205}$ By identifying this cluster of housing units under the same management and developing an upstream advocacy approach, which included legal advocacy and assisting tenants in forming tenant associations and engaging in advocacy, Child HeLP and its tenant clients were able to obtain: mold removal, pest abatement, window repairs, new roofs, ceiling and drywall renovations, replacement of sewage systems, air conditioning and ventilation system refurbishments, replacement of hallway lights, repairs to playground equipment, and emergency transfers for some tenants. ${ }^{206}$ These remedies went far beyond the individual housing conditions of each of their 16 cases, and significantly impacted the health and well-being of all tenants residing in these housing complexes, leading to "improvements at both the patient and community levels, facilitating treatment of both the 'sick child' and a portfolio of 'sick buildings.'"'207

Another example is the Health Justice Project (HJP), a medical-legal partnership between Loyola University Chicago School of Law, Legal Aid Chicago, and Erie Family Health Centers. They identified ongoing issues with childhood lead exposure in federally subsidized housing. ${ }^{208}$ In response, the HJP engaged in upstream advocacy in partnership with a national coalition to seek changes to the United States Department of Housing and Urban Development's (HUD) Lead Safe Housing Rule. ${ }^{209}$ The coalition successfully petitioned HUD to update its antiquated Rule to adopt the CDC's definition of lead poisoning, engage in data sharing between housing authorities and public health departments, and identify lead-exposed children in HUDfunded housing as soon as possible. ${ }^{210}$ These changes were adopted in January 2017, along with a requirement that a risk assessment

205. Id. at 832 .

206. Id.

207. Id. at 834 .

208. Kate Marple \& Erin Dexter, Keeping Children Safe from Lead Poisoning, NAT'L CTR. FOR Med.-Legal PARTNERShIP (Apr. 2018), https://medical-legalpartnership.org/wp-content/uploads/2018/ 04/Keeping-Children-Safe-from-Lead-Poisoning.pdf [https://perma.cc/7X3H-9546].

209. Id.

210. Id. 
be conducted on all units in a building in which a child has tested positive for lead poisoning. ${ }^{211}$

As demonstrated by these examples, interdisciplinary solutions are needed to address society's complex problems. Lawyers and health care providers working together can create impactful, sustainable solutions to such problems and improve the health and well-being of vulnerable communities in the process. Access to health care under EPSDT directly impacts the health and well-being of vulnerable children and is an area where MLPs can harness their interdisciplinary potential to engage in meaningful upstream advocacy.

\section{MLPs and EPSDT Advocacy}

MLPs are uniquely suited to identify and address EPSDT implementation issues because they provide a framework for meaningful education and collaboration among experts on Medicaid law and pediatric care. The MLP model lends itself particularly well to pediatric practice because the focus of pediatric care is, by its nature, holistic and preventive. In addition to assessing the health and stability of families and communities, pediatricians monitor a child's development, progress in school, nutrition, and mental, physical and oral health. ${ }^{212}$ Pediatricians watch patients transition from newborn infants to adults, sometimes even to parents and grandparents. ${ }^{213}$ The holistic focus of pediatricians may be the reason the first MLP and many other MLPs are based in pediatric and family care clinics.

A guiding force in the practice of pediatrics is the American Academy of Pediatrics' Bright Futures Guidelines for Health Supervision of Infants, Children and Adolescents (Bright Futures Guidelines). The Bright Futures Guidelines provide a roadmap

211. Id.

212. See generally Bright Futures Guidelines and Pocket Guide, BRIGHT Futures \& Am. ACAD. Pediatrics, .pdfs available at https:// brightfutures.aap.org/materials-and-tools/guidelines-and-pocketguide/Pages/default.aspx [https://perma.cc/Z283-6U6T] (last visited Feb. 24, 2019) [hereinafter Bright Futures Guidelines].

213. In one community pediatric clinic in which I worked during my employment with the Toledo Medical-Legal Partnership for Children in Ohio, the pediatricians commented on their familiarity with families through generations, one mentioning that she was providing care to a fourth generation of children. 
for pediatricians to screen, monitor and treat pediatric patients. ${ }^{214}$ But these guidelines are more than a treatment guide - they are evidence and theory based principles, tools, and strategies that "can be used to improve the health and well-being of all children through culturally appropriate interventions that address their current and emerging health promotion needs at the family, clinical practice, community, health system, and policy levels." 215

Bright Futures was created around 25 years ago when a "multidisciplinary group of pediatric health care experts and family representatives were asked to imagine our country's health picture if every child in America could look forward to a bright future-regardless of race, religion, background, income, politics, or any other factor." ${ }^{216}$ This multidisciplinary group developed a vision set forth in the Bright Futures Children's Health Charter, the basis for the first edition of the Bright Futures Guidelines. ${ }^{217}$

214. Bright Futures Guidelines, supra note 212.

215. Id.

216. About Bright Futures, BRIGHT Futures, https://brightfutures.aap .org/about/Pages/About.aspx [https://perma.cc/UC3Y-72NJ] (last visited Mar. 4, 2019).

217. Id. The Bright Futures Children's Health charter provides:

- Every child deserves to be born well, to be physically fit, and to achieve self-responsibility for good health habits;

- Every child and adolescent deserves ready access to coordinated and comprehensive preventive, health-promoting, therapeutic, and rehabilitative medical, mental health, and dental care. Such care is best provided through a continuing relationship with a primary health professional or team, and ready access to secondary and tertiary levels of care;

- Every child and adolescent deserves a nurturing family and supportive relationships with other significant persons who provide security, positive role models, warmth, love, and unconditional acceptance. A child's health begins with the health of his parents;

- Every child and adolescent deserves to grow and develop in a physically and psychologically safe home and school environment free of undue risk of injury, abuse, violence, or exposure to environmental toxins;

- Every child and adolescent deserves satisfactory housing, good nutrition, a quality education, an adequate family income, a supportive social network, and access to community resources;

- Every child deserves quality child care when her parents are working outside the home; 
The AAP Bright Futures charter urges advocacy and action in collaboration with community to promote health, improve the health care delivery system, and improve outcomes for children. ${ }^{218}$ These values closely align with those of social justice lawyers working to improve outcomes for vulnerable children through holistic legal advocacy. ${ }^{219}$

EPSDT is directly linked to these Bright Futures values as EPSDT requires that states adopt periodicity schedules and directly references the Bright Futures periodicity schedule for well-baby visits, or regular annual check-ups, for children from birth through adolescence. ${ }^{220}$ The well-baby-visit section of the Bright Futures Guidelines set forth opportunities for identifying

- Every child and adolescent deserves the opportunity to develop ways to cope with stressful life experiences;

- Every child and adolescent deserves the opportunity to be prepared for parenthood;

- Every child and adolescent deserves the opportunity to develop positive values and become a responsible citizen in his community;

- Every child and adolescent deserves to experience joy, have high self-esteem, have friends, acquire a sense of efficacy, and believe that she can succeed in life. She should help the next generation develop the motivation and habits necessary for similar achievement.

Bright Future's Children's Health Charter, BRIGHT Futures \& AM. ACAD. PEDIATRICS, https://www.brightfutures.org/charter.html [https://perma.cc/87LD-MLUK] (last visited Oct. 20, 2019).

218. Bright Futures Guidelines, supra note 212.

219. See Our Mission, LEGAL SERV. CORP., https://www.lsc.gov/aboutlsc/what-we-do [https://perma.cc/26U4-2WC7] (last visited Feb. 24, 2019) (explaining that Congress, in the declaration of purpose of the Legal Services Corporation Act, found that "there is a need to provide equal access to the system of justice in our Nation for individuals who seek redress of grievances"; that "there is a need to provide high quality legal assistance to those who would be otherwise unable to afford adequate legal counsel"; and, that "providing legal assistance to those who face an economic barrier to adequate legal counsel will serve best the ends of justice and assist in improving opportunities for low-income persons.").

220. See Bright Futures/AAP Recommendations for Preventive Pediatric Health Care (Periodicity Schedule), Bright Futures \& Am. ACAD. PEDIATRICs, https://downloads.aap.org/AAP/PDF/ periodicity_schedule.pdf [https://perma.cc/P9Q8-4Y4R] (last visited Feb. 18, 2019) (referencing the Bright Futures Guidelines for specific guidance by age). 
health concerns for children at regular intervals during monthby-month checkups for infants and annual checkups thereafter. ${ }^{221}$ Not only is EPSDT linked to the Bright Futures Guidelines in substance, but it is integral to the fulfillment of the guidelines and to the effective practice of pediatric medicine. Unfortunately, EPSDT is also a law that many pediatricians know little about as the intricacies of federal laws don't make it into medical school curriculum. ${ }^{222}$

I have seen these struggles firsthand. Over the years I have trained hundreds of pediatric providers on EPSDT in Toledo, Ohio and Ann Arbor, Michigan. Although many providers were aware of the basics of Medicaid, I learned that they were not aware of the intricacies of EPSDT or the full range of coverage EPSDT provides to their young patients. For example, some providers were shocked to learn of the broad coverage available to their patients and many expressed interest in developing tools to ensure appropriate coverage and care through advocacy. Others had adapted their practice over time to treat patients with services they perceived to be covered by insurance, often conceding that this resulted in less than optimal care for some patients. Attempting to capitalize on the excitement generated through newly acquired knowledge of EPSDT's potential, these trainings were the start of collaborative and interdisciplinaryupstream advocacy concerning EPSDT enforcement and access to care.

In a pediatric or family health care setting, an MLP can offer a mechanism for identifying EPSDT issues through training, consultations with medical providers, and collaborative advocacy work. MLP partners can advocate for coverage with MCOs, represent patients in administrative Medicaid appeals within MCOs or fair hearings before state Medicaid agencies, use of individual EPSDT cases or trends observed in practice to identify systemic implementation issues, and engage in upstream advocacy to improve the Medicaid system to the benefit of the

221. $I d$.

222. Susan Feiglman et al., Training Pediatric Residents in a Primary Care Clinic to Help Address Psychosocial Problems and Prevent Child Maltreatment, 11 ACAD. PEDIATRICs 474, 474-476, 478, 480 (2011). 
many. ${ }^{223}$ The following passages are examples of EPSDT cases that arose from my MLP collaborations. They demonstrate the systemic upstream impacts that are possible through interdisciplinary partnerships.

\section{Synagis Access in Ohio}

In the summer of 2009, The American Academy of Pediatrics changed its recommendations for the use of the drug Synagis (or Palivizumab), significantly narrowing its recommendations for use for infants born between thirty-two to thirty-five weeks gestation. $^{224}$ Synagis is a prophylactic medication given to prematurely born infants to protect their young, underdeveloped pulmonary systems from Respiratory Syncytial Virus (RSV), ${ }^{225}$ a common seasonal-respiratory infection that, while mildly aggravating to most healthy adults, can be life threatening or life altering to premature infants. ${ }^{226}$ From medical partners I learned that Neonatologists and Pediatric Pulmonologists were outraged by the changed recommendations, which they felt were largely based on cost-saving motivations rather than evidence and

223. See Jane Perkins, Update on EPSDT Litigation Trends, NATI'L Health L. Program (Nov. 9, 2018), https://healthlaw.org/ resource/update-on-epsdt-litigation-trends/ [https://perma.cc/ 936Y-GZHV]; Dayna B. Matthew, Ctr. For Health Pol'y at Brookings, The law as Healer: How Paying for MedicalLegal Partnerships Saves Lives AND Money 7 (2017).

224. Under the new guidelines, premature infants born between thirtytwo to thirty-five weeks gestational age were only recommended to receive synagis when they met certain risk factors, such as attending child care or living with siblings under 5 in the home. The prior guidelines set forth five risk factors making synagis more accessible to infants. The new guidelines also limited the dosage from 5 months to 90 days for children born after 32 weeks' gestation. MatThew, supra note 223; Policy Statement-Modified Recommendations for Use of Palivizumab for Prevention of Respiratory Syncytial Virus Infections, AM. ACAD. OF PEDIATRICS (2009), https://pediatrics.aappublications.org/content/pediatrics/ early/2009/09/07/peds.2009-2345.full.pdf [https://perma.cc/96Q9 -VRQZ].

225. What is SYNAGIS?, SYNAGIS, https://www.synagis.com/patients/ what-is-synagis.html [https://perma.cc/XE53-V66Z] (last visited Oct. 20, 2019).

226. Carrie Armstrong, AAP Updates Guidelines on Immunoprophylaxis for RSV Infection, 82 AM. FAM. PHYSICIAN 542 (2010). 
quality-of-care standards. ${ }^{227}$ The recommendations came out of an AAP communicable-disease-work group as opposed to a work group of more appropriate specialists, such as neonatologists and pediatric pulmonologists. ${ }^{228}$ The Ohio Medicaid program quickly adopted the recommendations and limited when it would cover Synagis for Medicaid-eligible infants. ${ }^{229}$ So, in accordance with the new guidance, MCOs began to deny Synagis-preauthorization requests for premature infants that did not satisfy the standard.

In the Fall of 2009, the Toledo Medical Legal Partnership for Children (MLPC), an MLP based within Advocates for Basic Legal Equality (and previously Legal Aid of Western Ohio), ${ }^{230}$ began to receive referrals from its partners at Mercy Children's Hospital's Pediatric Pulmonary Clinic for preauthorization denials of Synagis by a particular MCO. ${ }^{231}$ The providers conducted peer-to-peer reviews with the MCO that issued the denials, filed appeals with the $\mathrm{MCO}$ on behalf of the infant beneficiaries, and, after continued denials, referred families to the MLPC for representation in fair hearings before the Ohio Department of Job and Family Services. ${ }^{232}$ The MLPC worked in collaboration with the pediatric pulmonary specialists, filing fair hearing requests on behalf of two families facing denials of Synagis and providing supportive medical records and documentation of the medical research and controversies regarding the new AAP

227. Leonard Krilov et al., The 2009 COID Recommendations for RSV Prophylaxis: Issues of Efficacy, Cost, and Evidence-Based Medicine, 124 PEDIATRICs 1682-84 (2009).

228. $I d$.

229. ABLE and LAWO File Federal Complaint On Behalf of Ohio Premature Infants, ADvoc. For BASIC LEGAL EQ., InC. (March 29, 2011), https://www.ablelaw.org/media-room/news-and-pressreleases/2011-news-archive-getinformation-1250/2736-able-andlawo-file-federal-complaint-on-behalf-of-ohio-premature-infants [https://perma.cc/23YV-BNZF].

230. Medical-Legal Partnership for Children, ADVOC. FOR BASIC LEGAL EQ., INC., http://www.ablelaw.org/able-services/medical-legalpartnership [https://perma.cc/9KGW-A8K6] (last visited Sept. 13, 2019).

231. Provider Source, CARE SOURCE, https://www.caresource.com/ documents/providerchoicenewsletterfall2009-pdf/ [https://perma .cc/B5AQ-MG6G] (last visited Feb. 20, 2020).

232. Id. 
Synagis guidelines. ${ }^{233}$ The treating pulmonologist provided an affidavit in support of coverage and his nurse practitioner testified at the state fair hearing. ${ }^{234}$ After the hearing, the Administrative Law Judge remanded the case to the MCO for a new determination. The MCO again issued denials and the appeals process began again. By the time the second appeal process was completed, Synagis was no longer necessary because RSV season had ended and there was no point in further appeals to obtain the medication. ${ }^{235}$

The following RSV season, the MLP team decided to take a more aggressive advocacy approach challenging the Synagis denials by bypassing the ineffective state hearing system and filing an action in federal court. ${ }^{236}$ During the Fall of 2010, when prematurely born Medicaid-eligible infants began to receive denials for Synagis, the interdisciplinary team was waiting with a strategy. ${ }^{237}$ The MLPC attorneys filed an action for a temporary restraining order in federal court on behalf of two prematurely born infants denied Synagis by their MCO plan. ${ }^{238}$ Within minutes of the initial conference call with the assigned judge, the judge strongly encouraged the state to provide "the babies their shots," and the case was resolved shortly thereafter with agreed approvals for Synagis for the infant clients. ${ }^{239}$ While national efforts to pressure the AAP to reconsider its Synagis guidelines continued, medical providers within the Mercy pulmonary clinic began to see success with Synagis preauthorization requests to

233. Id.

234. Affidavit for Plaintiff, R.M. et al. v. Colbert, No. 3:11-cv-00632 (N.D. Ohio filed Mar. 29, 2011).

235. See Provider Source, supra note 231.

236. Success Stories: Jack, The Toledo MedicAl-Legal P'ShIP FoR ChILDREN, https://mlpc.ablelaw.org/toledo/jack/ [https://perma .cc/58VW-BSVA] (last visited Oct. 20, 2019).

237. Id.

238. Brief for Plaintiff, R.M. et al. v. Colbert, No. 3:11-cv-00632 (N.D. Ohio filed Mar. 29, 2011).

239. Telephone conference: R.M. et al. v. Colbert, No. 3:11-cv-00632, held by Judge David A. Katz (Mar. 31, 2011). 
the MCO. ${ }^{240}$ The providers were empowered to advocate for appropriate coverage for their patients under EPSDT and the MCO deferred to the providers preauthorization requests for Synagis from that point on.

\section{Related Therapy Access in Michigan}

Savannah, an eight-year old patient of the Michigan Medicine Pediatric Rehabilitation Center, was referred to the Pediatric Advocacy Clinic, an MLP clinic at the University of Michigan Law School, ${ }^{241}$ for assistance with a Medicaid appeal of denials of related therapies. ${ }^{242}$ Savannah has Rett syndrome ${ }^{243}$ and DiGeorge syndrome, ${ }^{244}$ two complex conditions that cause significant developmental delays and complex medical issues. ${ }^{245}$ Girls with Rett Syndrome start out on-track developmentally for the first year or so of life but then rapidly regress. ${ }^{246}$ Savannah had been receiving speech, occupational and physical therapy for most of

240. See, e.g., Jack, MLPC MiAmi VALLEY, https://mlpc.ablelaw.org/ miamivalley/jack/ [https://perma.cc/39FU-C9YK] (last visited Oct. 29, 2019).

241. Pediatric Advocacy Clinic, U. Mich. LAw, https://www.law.umich .edu/clinical/pediatricadvocacyclinic/Pages/default.aspx [https:// perma.cc/3NAP-AMAZ] (last visited Sept. 13, 2019).

242. Katie Vloet, Doctor's Orders: Call Your Lawyer, L. QuAdRAngle: Notes FROM Mich. L., http://quadrangle.law.umich.edu/spring 2015/features/doctors-orders-call-your-lawyer/ [https://perma.cc/ 6S5Y-JK7R] (last visited Feb. 20, 2020).

243. Rett Syndrome, which almost exclusively affects girls, causes the same mental and developmental limitations often associated with the most severe forms of autism, including a lack of oral, written, or other communication abilities. Rett Syndrome Fact Sheet, NAT'L Inst. OF NeUrological Disorders AND Stroke, https:// www.ninds.nih.gov/disorders/patient-caregiver-education/factsheets/rett-syndrome-fact-sheet [https://perma.cc/KR8U-M7YL] (last visited Feb. 24, 2018) [hereinafter Rett Syndrome Fact Sheet].

244. DiGeorge syndrome is a congenital chromosomal condition that can cause facial abnormalities, heart disease, susceptibility to infections and other medical and behavioral issues. DiGeorge Syndrome, MAYO CLINIC, https://www.mayoclinic.org/diseases-conditions/ digeorge-syndrome/symptoms-causes/syc-20353543 [https:// perma.cc/VK7Z-27PQ] (last visited Feb. 24, 2018).

245. Vloet, supra note 242.

246. Rett Syndrome Fact Sheet, supra note 243. 
her life. ${ }^{247}$ Shortly after she was transitioned from the state-run Medicaid program to an MCO, however, she was suddenly denied these related therapies because the MCO deemed the services "habilitative" and of the type that should be provided in school as part of her special education program. ${ }^{248}$

The PAC collaborated with Savannah's medical providers to gather support for continued related therapies and appealed the denials in a fair hearing before the Michigan Department of Health and Human Services (DHHS). ${ }^{249}$ During the appeal, the PAC presented medical records showing that continued therapies were medically necessary under EPSDT so Savannah could improve in mobility, self-care and communication, and to prevent regression of acquired skills. ${ }^{250}$ The PAC further argued that the habilitative standard did not apply to children and that the medical standard for related services was not related to the educational standards used by the school district to determine services necessary to receive a free and appropriate public education under special education laws. ${ }^{251}$ The Administrative Law Judge (ALJ) overseeing the hearing was unfamiliar with EPSDT and, though provided the law in the hearing and in a post-hearing brief, ruled against Savannah and upheld the MCO denials. $^{252}$

Faced with the question of whether to appeal the ALJ decision to the state circuit court or engage in other advocacy efforts, the PAC considered information from medical partners regarding a growing, pervasive issue related to Medicaid-eligible children being denied occupational, physical, and speech therapies by MCOs because they were deemed habilitative rather than rehabilitative. ${ }^{253}$ Upon review of the state's Medicaid manual, it became clear that the manual did not sufficiently distinguish

247. Vloet, supra note 242.

248. Id.

249. Id.

250. $I d$.

251. Id. A free and appropriate public education, often referred to as a "FAPE," is a component of the Individuals with Disabilities Education Act of 1990, as amended. See 20 U.S.C. $\$ 1432$ (2018).

252. Vloet, supra note 242.

253. Id. 
between related therapy coverage standards for children under EPSDT and coverage for adults. ${ }^{254}$ In contravention of the law, MCOs were using the adult standard which only covered rehabilitative therapies. ${ }^{255}$ After consultation with national experts, it became clear to our team that upstream advocacy provided the ideal approach to addressing these policy ambiguities. The PAC drafted a letter to the state department of Medicaid and the United States Center for Medicaid and Medicare Services regarding Savannah's case, MCO practices in Michigan, and the problematic language in the state medical plan policies. ${ }^{256}$ Within days of sending the letter, the PAC received responses from the state and from CMS, both conceding that the rehabilitative standard did not apply to children and that the state Medicaid plan was unclear and in need of revision. ${ }^{257}$ Michigan also agreed that Savannah was eligible for the related therapies prescribed by her doctors. ${ }^{258}$

Over the course of the next year, Michigan amended its MCO manual to clarify that the related therapy standard for children was different than the adult standard and did include habilitative services. ${ }^{259}$ It then issued policy statements and guidance to MCOs and providers as necessary. ${ }^{260}$ The PAC continued to meet monthly with Michigan Medicine's related therapy providers in the Pediatric Rehabilitation Center to monitor the implementation of these new guidelines and to enable identification of new EPSDT related health access issues.

\section{Pediatric Hospital Bed Access in Ohio}

Jill was referred to the MLPC in Toledo, Ohio for assistance with a Medicaid appeal for her daughter, Tracy, ${ }^{261}$ a seven-year old with autism, spina bifida, a shunt, and chronic clostridium

254. Id.

255. See id.

256. Id.

257. Id.

258. Id.

259. $I d$.

260. $I d$.

261. The names being used in this story have been altered to protect the anonymity of the clients that I represented in this case. 
difficile colitis. Despite her conditions, Tracy moved constantly: crawling, scooting, wiggling, and pulling herself up on things. Tracy slept in a crib, supported underneath by boxes to keep her from falling through to the ground, so Tracy's pediatrician prescribed a specialized pediatric hospital bed with high solid railings, a top enclosure, and the capacity to move up and down for care. Although the bed would have dramatically improved Tracy's quality of life - and Jill's ability to care for her - the state Medicaid plan denied the physician preauthorization request for the bed, indicating that Tracy should try lower cost bed options. Lower cost bed options had been considered by the doctor but were ruled out due to Tracy's care needs and safety concerns. ${ }^{262}$

During the process of advocating for coverage for Tracy's bed with the Ohio department of Medicaid, the MLPC contacted nearly twenty durable medical equipment (DME) providers searching for lower cost pediatric hospital bed options. While talking to DME providers both in and out of Ohio, the MLPC learned that DME providers were not providing any pediatric hospital beds to Medicaid-eligible children in Ohio because the state reimbursement rate was lower than the cost of the beds, and significantly lower than the cost of the bed prescribed for Tracy. Other DME providers were unwilling to even submit a preauthorization request to Ohio Medicaid due to the low reimbursement. As a result, no child on Medicaid was receiving a Medicaid covered pediatric hospital bed in the state of Ohio.

Armed with medical records documenting the medical necessity of the prescribed bed and information regarding the lack of access to pediatric hospital beds in the state, the MLPC approached legal counsel for the state department of Medicaid regarding its concern that no Medicaid-eligible child in the state was getting a pediatric hospital beds due to the Medicaid reimbursement rate and, specifically, that Tracy was being put at risk of serious and potentially life threatening harm without an

262. For example, the solid rails would address Tracy's spina bifida, which affected her ability to feel injuries if she were to get her legs or feet caught in a standard hospital bed railing. The bed's high railings and enclosure would prevent Tracy from climbing out and falling, a potentially life-threatening event due to the shunt in her head. Finally, the bed's adjustable height would facilitate the numerous medical procedures that she required each day, such as catheterization and regular diaper changes. 
appropriate bed. The efforts were a success: The state approved coverage for Tracy's bed at cost and made a commitment that the state reimbursement rate would change to enable other medically-fragile children to access pediatric hospital beds.

These EPSDT cases reflect the potential for MLPs to identify EPSDT coverage issues and improve the systems implementing EPSDT through collaboration and upstream advocacy. Because our medical-legal teams analyzed the policies and practices at the root cause of the coverage issues for individual patient/clients we were able to develop strategies to address those root causes for the benefit of the larger Medicaid population. EPSDT coverage challenges emerge most consistently for children with chronic and severe medical issues and disabilities because they are particularly vulnerable and in great need of EPSDT covered care. While other legal aid and advocacy organizations also engage in critical EPSDT advocacy, pediatric and family practice MLPs are particularly well positioned to hold Medicaid systems accountable to children.

\section{MLPs as EPSDT Monitors and Advocates}

Medical-legal partnerships can facilitate much needed comprehensive ESPDT monitoring and advocacy by leveraging the relationships of legal experts on Medicaid and medical experts on pediatric care to identify implementation and coverage gap issues. Given EPSDT's complexity, the intricacies of medicalnecessity determinations, the ever-changing standards of medical care, widespread EPSDT implementation issues, and the bureaucratic systems of peer-to-peer reviews and administrative appeals, EPSDT is ripe for advocacy by MLPs. MLPs can jumpstart EPSDT advocacy initiatives by engaging in provider training on EPSDT, supporting providers in advocacy efforts, engaging in direct advocacy on behalf of patients, and facilitating collaborative upstream advocacy efforts to address systemic and pervasive implementation issues. Note, similar coverage issues exist for Medicaid eligible adults and MLP advocacy for Medicaid enforcement for adults is also absolutely necessary. This article, however, focuses on pediatric care, EPSDT, and opportunities for advocacy to enforce its broad coverage requirements.

\section{a. Training}

Training medical providers on EPSDT is a critical first step in monitoring state EPSDT coverage. As most pediatric providers 
are not aware of the broad coverage mandated by EPSDT, providers are unable to identify issues related to coverage errors to refer to their legal teams unless they are trained to identify the EPSDT issues. As providers are trained on EPSDT and the range of screening, preventive, diagnostic, treatment, and ameliorative services mandated by it, they can begin to identify issues in coverage determinations for their patients. Health care providers need training not only on the sweeping coverage requirements of EPSDT, but also on the medical necessity determination process. Providers need to be made aware of the process for preauthorization requests, how to leverage requests to maximize chances of approval, and of the importance of record-keeping. Finally, providers need to know how to educate patients regarding their right to care and to appeal denials of coverage for care.

Even after engaging in training on the basics of EPSDT and procedures for coverage determinations, it is helpful for the legal team to become integrated with the health care providers in some way to facilitate ongoing sharing of information and consultations. While at the University of Michigan Pediatric Advocacy Clinic, I embedded myself in the Pediatric Medicine and Rehabilitation clinic by meeting monthly with providers at the clinic to discuss their Medicaid coverage frustrations. It is important to remember that medical providers are not attorneys. In my experience, this means that even after training, providers do not always identify EPSDT issues. Some would indicate that there were no legal issues or questions to discuss with me, and then go on to describe frustrations with MCO coverage decisions and practices that indicated significant EPSDT compliance issues. My presence and engagement in discussions about billing and coverage frustrations were the primary way that we uncovered continuing issues. I also developed a close, consultative relationship with the clinic social worker who engaged in extensive communication and advocacy with the MCOs on preauthorization decisions. Through training and support, she too was able to be more effective in her own advocacy and obtaining coverage for her patients.

\section{b. Encourage and Facilitate Provider Advocacy}

Once armed with knowledge about EPSDT, it is critical to encourage and facilitate health care provider advocacy to enhance coverage for patients. The more providers who are armed with 
knowledge of EPSDT coverage requirements, and who are engaged in advocacy to ensure access to appropriate care and services for patients, the more that Medicaid systems and MCOs will be held accountable to fulfill their obligations to Medicaideligible children. MLP attorney partners can facilitate this advocacy by being available to providers for consultations and by developing tools and resources to support providers in their advocacy.

The Toledo Medical-Legal Partnership for Children, and the Pediatric Advocacy Clinic (PAC) at the University of Michigan Law School, both developed physician guides for medical partners which continue to provide guidance on EPSDT, how coverage decisions are made, the role and functioning of MCOs, and tips for ensuring coverage for patients. ${ }^{263}$ The PAC guide also includes a sample appeal letter, contact information for $\mathrm{MCO}$ contract managers in the state Medicaid program, and a table with MCO hearing and state fair hearing guidelines. ${ }^{264}$ These sorts of resources support providers engaging in advocacy and give them the tools necessary to push back against MCOs and state Medicaid coverage denials.

Providers are also more inclined to engage in EPSDT advocacy when they know that a legal team has their back. Integrating a member of the legal team with the health care system can facilitate this. When there is a knowledgeable, familiar face present for consultations, providers tend to feel more empowered to engage in patient advocacy. Assisting in reviewing cases, providing feedback on advocacy letters, and providing advice and suggestions to providers handling informal advocacy, peer-to-peer reviews, and appeals further facilitates provider advocacy. Another critical component of empowering providers

263. See Medical Provider FAQ: Navigating Medicaid for Pediatric Patients, Mich. L. Pediatric Advocacy Clinic, https:// www.law.umich.edu/clinical/pediatricadvocacyclinic/Documents/ EPSDTProvider\%20FAQ.pdf [https://perma.cc/6YH4-YVS5] (last visited Mar. 5, 2019); Disability Rights OHIO AND THE Toledo Med.-L. P'ship FOR Children, Physician Guide to Navigating the Medicaid Managed Care System for Medicaid Eligible Pediatric Patients, available at http://mlpc.ablelaw .org/toledo/wp-content/uploads/2017/05/MLPC-DRO-physician guide-050817.pdf [https://perma.cc/4U88-FP2U] [hereinafter Medicaid Managed Care System].

264. Medicaid Managed Care System, supra note 263. 
to engage in advocacy is engaging in direct advocacy and representation of their patients when provider efforts fall short. Providers who see the positive effects of advocacy by attorneys and the positive impact on patient care can be motivated to engage in more advocacy themselves.

\section{c. Engage in Direct ESPDT Advocacy}

When a health care provider's advocacy effort is ineffective, it is critical that the legal team be ready to step in to take the case and engage in direct services and advocacy for coverage. MLP attorneys can develop expertise in EPSDT and file administrative appeals within MCOs and fair hearing requests before state Medicaid agencies. Health provider partners are critical to this direct advocacy work as the health care providers can offer evidence from medical records, affidavits in support, and testify at hearings. Participation in the hearing preparation process and in the hearings themselves also further educate providers on the intricacies of EPSDT, the administrative process, and the benefits to patients and patient care.

Another pediatric hospital bed case handled by the PAC at the University of Michigan Law School demonstrated the power of interdisciplinary collaboration in individual advocacy work. The legal team worked closely with the medical team to build the record and to make the case that a pediatric specialty bed was medically necessary for a young boy with autism and complex medical needs. At the hearing, the social worker and the physical medicine and rehabilitation fellow provided critical testimony to counter the testimony and arguments of the MCO attorneys and medical director. Because of their careful and collaborative preparation, the PAC was successful in getting an order that the MCO provide the specialty pediatric hospital bed to the patient. Without the hard work of the medical team engaging in direct advocacy with the MCO for over a year-compiling evidence and providing free, expert consulting and testimony on the medical conditions - the outcome may have been different.

\section{d. Engage in Upstream Advocacy}

A final, critical component of MLP-led EPSDT monitoring and advocacy is upstream, or systems-focused, advocacy. As health and legal providers engage in EPSDT monitoring and advocacy, systems related issues are likely to emerge, indicating that certain state and MCO policies and practices are inconsistent 
with EPSDT more generally. In such cases, it is sometimes most effective for medical-legal advocacy teams to engage in upstream advocacy efforts to address the root cause of the issues resulting in coverage denials, rather than litigate the claim directly. This can involve informal advocacy with state Medicaid agencies, comments on proposed state and federal regulations related to EPSDT implementation, and impact litigation at the state and federal level, much like many of the cases described in Part II of this article. Upstream advocacy is enhanced by collaborations between EPSDT legal experts and pediatric practice experts because of the wealth of knowledge and credibility of the two professions which can encourage responsiveness among agency administrators, policy makers, and judges

The multi-tiered approach to EPSDT monitoring and advocacy promoted by both lawyers and health care providers can assist in addressing EPSDT implementation failures. Widespread awareness of EPSDTs requirements among the health providers prescribing services, equipment, prescriptions, and treatments, coupled with the direct and systemic advocacy skills of MLPs, has the potential to hold states more accountable to their EPSDT mandates.

\section{CONCLUSION}

The broad historic focus of EPSDT on holistic and preventive services has been only partially effectuated by states. As states develop and evolve their Medicaid plans and practices, for example, by entering contracts with MCOs and searching to cut costs, the great promise of comprehensive and preventive health care services for children in poverty still alludes us. MLPs can play a critical role in helping EPSDT reach its promise by educating health care providers on EPSDT, engaging health care providers and lawyers in direct and systemic advocacy, and holding states accountable to their obligations to Medicaideligible children. 
